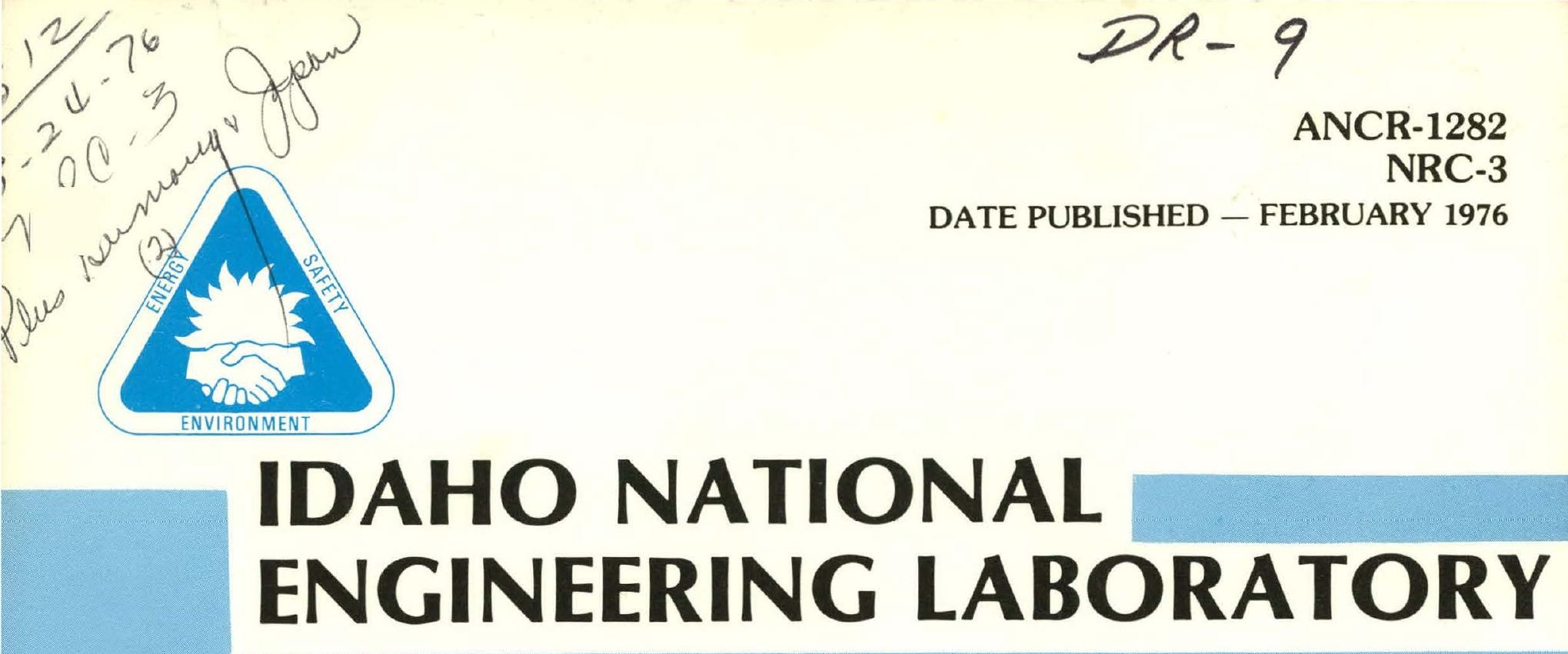

\title{
NONDESTRUCTIVE EXAMINATION OF IRRADIATED FUEL RODS BY PULSED EDDY CURRENT TECHNIQUES
}

\section{U. S. NUCLEAR REGULATORY COMMISSION}




\section{DISCLAIMER}

This report was prepared as an account of work sponsored by an agency of the United States Government. Neither the United States Government nor any agency Thereof, nor any of their employees, makes any warranty, express or implied, or assumes any legal liability or responsibility for the accuracy, completeness, or usefulness of any information, apparatus, product, or process disclosed, or represents that its use would not infringe privately owned rights. Reference herein to any specific commercial product, process, or service by trade name, trademark, manufacturer, or otherwise does not necessarily constitute or imply its endorsement, recommendation, or favoring by the United States Government or any agency thereof. The views and opinions of authors expressed herein do not necessarily state or reflect those of the United States Government or any agency thereof. 


\section{DISCLAIMER}

Portions of this document may be illegible in electronic image products. Images are produced from the best available original document. 
Printed in the United States of America

$$
\text { Available from }
$$

National Technical Information Service

U. S. Department of Commerce

5285 Port Royal Road

Springfield, Virginia 22161

Price: Printed Copy $\$ 4.50$; Microfiche $\$ 2.25$

APPROVED:

$\frac{S \text { Colven for }}{\text { H. W. Campen }}$

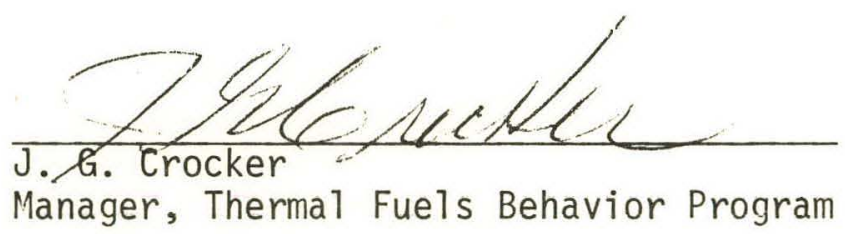

\section{NOTICE}

This report was prepared as an account of work sponsored by the United States Government. Neither the United States nor the Energy Research and Development Administration, nor the Nuclear Regulatory Commission, nor any of their employees, nor any of their contractors, subcontractors, or their employees, makes any warranty, express or implied, or assumes any legal liability or responsibility for the accuracy, completeness or usefulness of any information, apparatus, product or process disclosed, or represents that its use would not infringe privately owned rights. 


\section{NONDESTRUCTIVE EXAMINATION OF IRRADIATED FUEL RODS BY PULSED EDDY CURRENT TECHNIQUES}
W. C. Francis
M. R. Martin
W. J. Quapp
G. W. Gibson

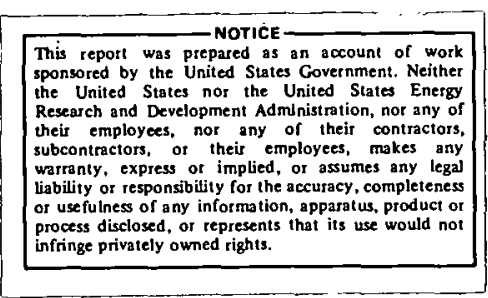

AEROJET NUCLEAR COMPANY

Date Published - February 1976

PREPARED FOR THE

U.S. ENERGY RESEARCH AND DEVELOPMENT ADMINISTRATION

IDAHO OPERATIONS OFFICE

UNDER CONTRACT NO. E(10-1)-1375 


\section{ACKNOWLEDGMENTS}

The important contributions of W. H. Love and G. A. Rigby of the Matcrials Technology Branch in making the PEC scans and in reducing the voluminous dala lu simplified spacial charts is gratefully acknowledged. W. H. Love also contributed portions of the operating procedure.

N. S: Abbott and L.V. Wages of the Quality Division contributed extensively in the evaluation of the scan data. Abbott and one of the authors (Francis) provided the level III (ASTNT TC-1A) guidance for the project. 


\begin{abstract}
A number of fuel rods and unfueled zircaloy cladding tubes which had been irradiated in the Saxton reactor have undergone extensive nondestructive and corroborative destructive examinations by Aerojet Nuclear Company as part of the Water Reactor Safety Research Program, Irradiation Effects Test Series. This report discusses the pulsed eddy current (PEC) nondestructive examinations on the fuel rods and tubing and the metallography results on two fuel rods and one irradiated zircaloy tube. The PEC equipment, designed jointly by Argonne National Laboratory and Aerojet, performed very satisfactorily the functions of diameter, profile, and wall thickness measurements and OD and ID surface defect detection. The destructive examination provided reasonably good confirmation of "defects" detected in the nondestructive examination.
\end{abstract}




\section{CONTENTS}

ACKNOWLEDGMENTS $\ldots \ldots \ldots \ldots \ldots \ldots \ldots$ ii

ABSTRACT $\ldots \ldots \ldots \ldots \ldots \ldots \ldots \ldots \ldots \ldots \ldots \ldots \ldots$ iii

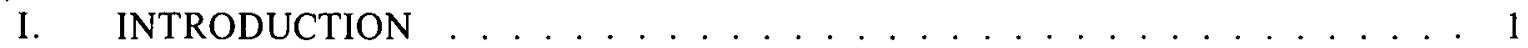

II. SUMMARY AND CONCLUSIONS $\ldots \ldots \ldots \ldots \ldots \ldots$

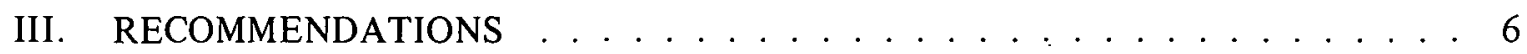

IV. EXPERIMENTAL EQUIPMENT AND PROCEDURES $\ldots \ldots \ldots \ldots$

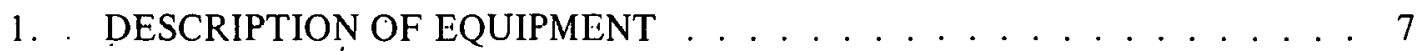

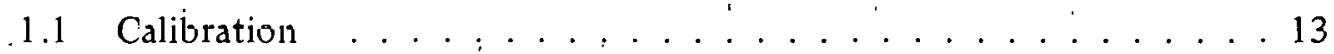

2. TEST PROCEDURE . . . . . . . . . . . . . 17

V. TEST RESULTS . . . . . . . . . . . . . . . . . . . 21

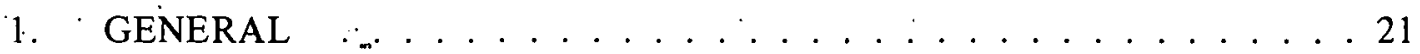

2. ROD EXAMINATION $\ldots \ldots \ldots \ldots \ldots \ldots \ldots \ldots \ldots \ldots \ldots$

2.1 Fuel Rods . . . . . . . . . . . . . . . . . . . 21

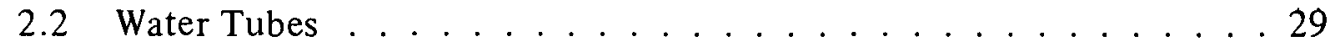

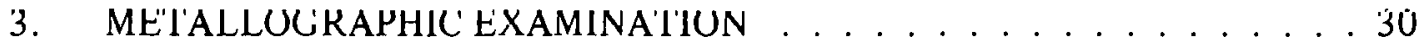

3.1 Fuel Rods . . . . . . . . . . . . . . . . . . . . . . . . 30

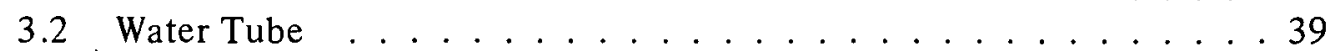

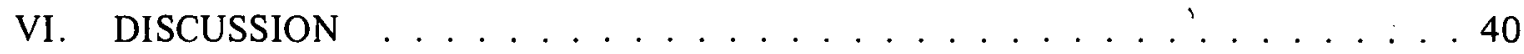

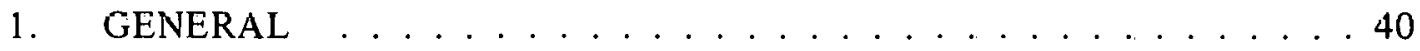

2. LIMITATIONS OF TECHNIQUES $\ldots \ldots \ldots \ldots \ldots$

3. EQUIPMENT LIMITATIONS $\ldots \ldots \ldots \ldots \ldots$

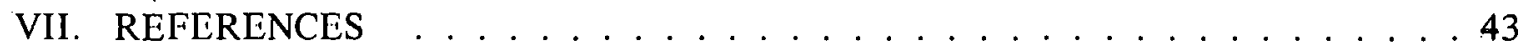

APPENDIX - SUMMARIZED OPERATING PROCEDURE FOR PEC $\ldots \ldots \ldots . \ldots 45$

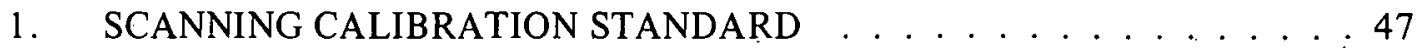

2. SCANNING FUEL ROD OR WATER TUBBE $\ldots \ldots \ldots \ldots$ 


\section{FIGURES}

1. Typical fuel rod ................... 2

2. Fuel rod characterization flow chart ................. 4

3. Pulsed Eddy Current (PEC) electro-mechanical scanner . . . . . . . . . 8

4. PEC servo-mechanism for positioning sensor coils . . . . . . . . . . . . . . 9

5. PEC sensors for ID and OD defect inspection and tube thickness

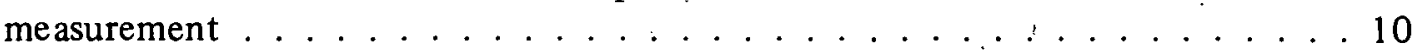

6. Axial and azimuthal orientation of PEC sensors ............ 11

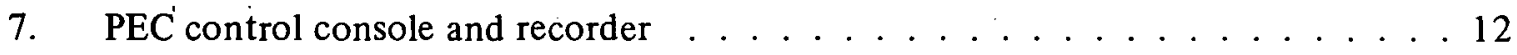

8. Calibrating standard for cladding thickness ............... . 14

9. PEC thickness scans showing end-toend and circumferential variations

in a ty pical fuel rod cladding . . . . . . . . . . . . 15

10. Fuel rod straightness standard .................. 16

11. Scan of PEC calibration rod for surface defects and clad thickness

(230-degree orientation for ID defects) . . . . . . . . . . . 18

12. Scan of PEC calibration rod for surface defects and clad thickness

(50-degree orientation for OD defects) . . . . . . . . . . . 19

13. Simplified defect chart of load-follow fuel rod $864 \ldots . . \ldots 20$

14. Pseudo map of water tube STD-50 . . . . . . . . . . . . . 22

15. Pseudo map of water tube No. $5 \ldots \ldots \ldots$

16. Partial pseudo map of load-follow fuel rod $864 \ldots \ldots$. . . . . . . . . . 24

17. Simplified defect chart of MAPI fuel $\operatorname{rod} \mathrm{M} 22 \ldots \ldots . \ldots . \ldots$

18. Micrograph of 0.0008 -inch-deep defect found on inside of water tube

STD-50 at 215-degree orientation . . . . . . . . . . . . . 27

19. Micrograph of grooves found on OD of water tube STD-50 in Sample M-3

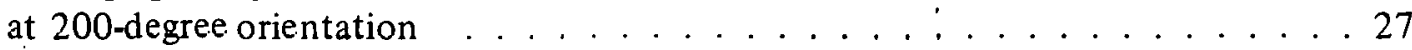

20. Micrographs of ID defects found in water tube STD-50 in Sample M-3

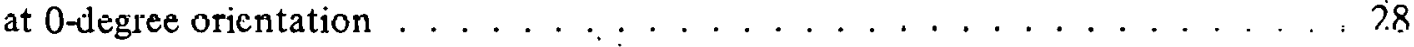


21. Simplifed defect chart of load-follow fúel $\operatorname{rod} 837 \ldots \ldots$. . . . . . 31

22. Sectioning diagram - water tube STD-50 . . . . . . . . . . 32

23. Sectioning diagram - load-follow fuel $\operatorname{rod} 864 \ldots \ldots 33$

24. Sectioning diagram - load-follow fuel $\operatorname{rod} 837 \ldots \ldots . \ldots . \ldots$

25. Longitudinal Section $\mathrm{M}-1$ prepared from fuel rod 837 showing defect in surface of cladding . . . . . . . . . . . . . . . . 35

26. Micrograph of surface defect found in Section M-1 of fuel rod 837,

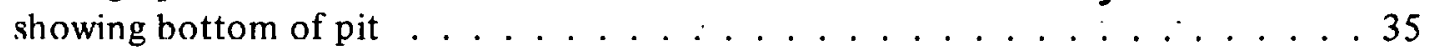

27. Micrograph of longitudinally-oriented groove found on OD surface of fuel rod 837 in Specimen M-3 . . . . . . . . . . . . . . . . . 36

28. Micrograph of surface defect found on OD of fuel rod 837 in

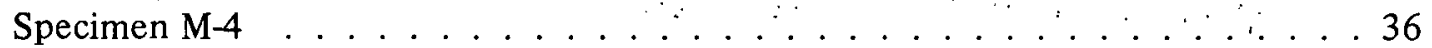

29. Micrograph of cladding of fuel rod 837 taken 90 degrees from area shown in Figure 28, showing surface hydride layer .. . . . . . . . . . . . . 37

30. Micrograph of cladding of fuel rod 864 showing corrosion product on surface 


\section{NONDESTRUCTIVE EXAMINATION OF IRRADIATED FUEL RODS BY PULSED EDDY CURRENT TECHNIQUES}

\section{INTRODUCTION}

Aerojet Nuclear Company (ANC) at the Idaho National Engineering Laboratory (INEL) is conducting fuel rod behavior studies as part of the Nuclear Regulatory Commission's Water Reactor Safety Research Fuel Behavior Program. Data on fuel rod performance are being obtained under a wide range of normal, off-normal, and accident conditions in order to provide data for verification and further development of fuel rod behavior models.

A number of unirradiated and irradiated fuel rods and irradiated unfueled zircaloy cladding tubes (water tubes) were obtained from the Saxton reactor through arrangements with the Westinghouse Electric Corporation for use in the Irradiation Effects (IE) Test Program [1].

Before using the fuel rod materials in the IE program a comprehensive nondestructive characterization program has benn undertaken on these fuel rods and tubes by ANC to provide baseline data on their characteristics prior to further testing and for comparison with posttest data.

A typical fuel rod is illustrated in Figure 1. The assembly of dished $\mathrm{UO}_{2}$ fuel pellets is clad with zircaloy 4 .

Fuel enrichments, internal gas pressure, and burnùp varied among the rods. Because of . the limited number of fuel rods and "water tubes" available, great emphasis was placed on a thorough nondestructive testing (NDT) program, although some destructive examinations were performed. This report describes one portion of the NDT program performed remotely in the hot cells on the irradiated fuel rods and water tubes. Figure 2 summarizes all of the examinations performed, in flow sheet form.

The pulsed eddy current (PEC) method was selected for use in the nondestructive inspection of irradiated Saxton fuel rods and water tubes for internal and external surface defects, cladding thickness, and rod deformation. This method was developed at the Argonne National Laboratory (ANL) $[2,3,4]$ and has also been used by General Electric (GE) at the Vallecitos Nuclear Center to inspect irradiated fuel rods ${ }^{[5]}$.

The PEC method of inspection was chosen for the inspection of these rods since it was expected to:

(1) detect cladding microcracking,

(2) detect fuel-cladding interaction, 


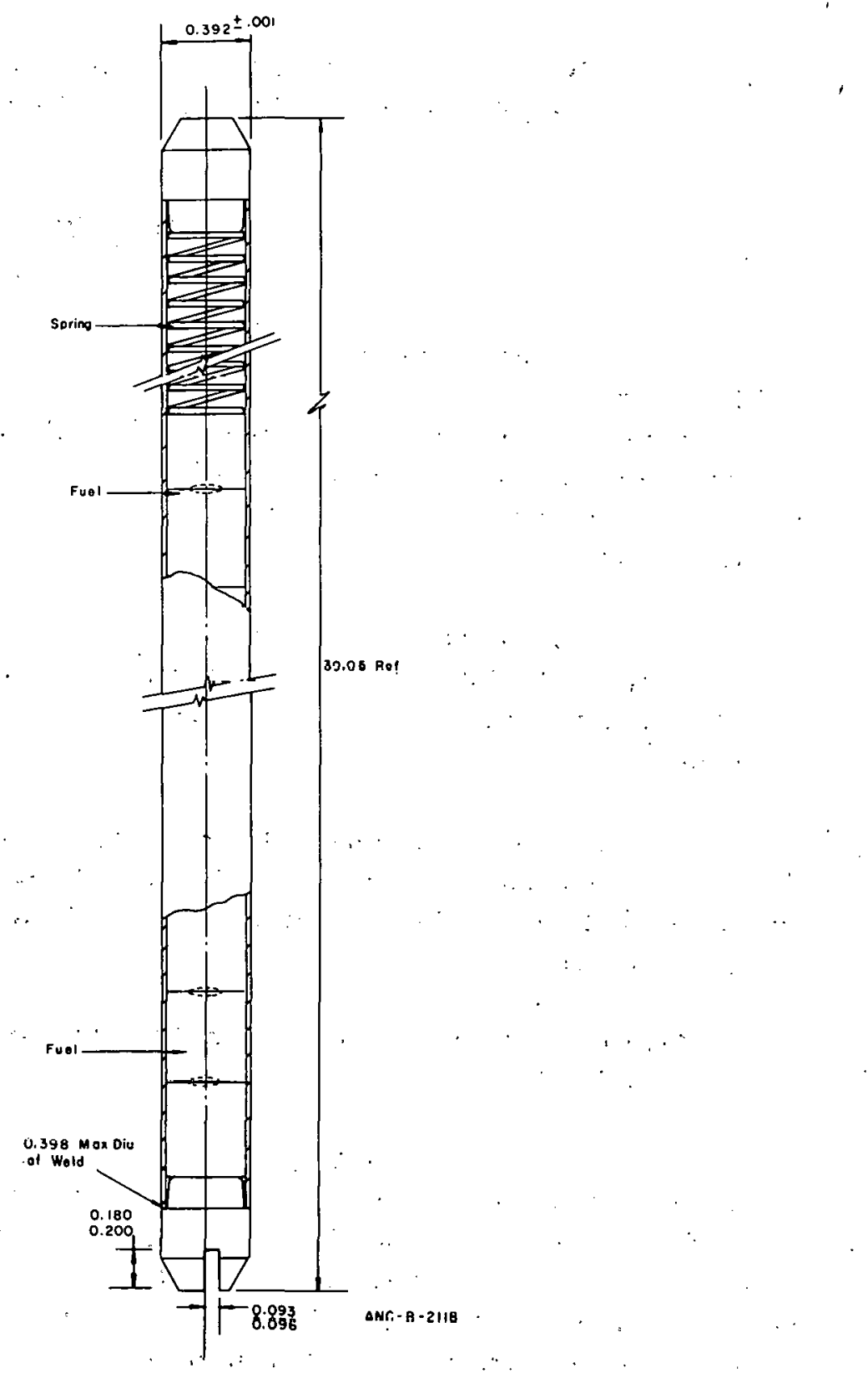

Fig. 1 Trpical fuel rod (all dimensions in inches).

(3) determine cladding thickness, and

(4) nperate in a dry environment and therefore be readily adaptable to hot cell installation and usage.

The PEC system was selccted in preference to ultrasonic techniques (UT) because of its adaptahility to remote operation and because of the reported good results obtained by ANL and GE in its use. The UT..approach had been considered on the basis of work at Chalk River on irradiated fuel inspection ${ }^{[6]}$. Sensitivity for both ID and OD defects by UT inspection was reported to be excellent in the AECL reference but the PEC system was more attractive because of its special advantages: (a) rapid scanning [approximately $45 \mathrm{~mm}$ (1.77 in.)/sec], (b) good circumferential accuracy (10-degree); and (c) single scan to provide 
both longtudinal and transverse defect data. Reference 6 indicated that scanning was done in the longitudinal mode only. It would, of course, have been a simple matter to reorient the UT transducer to provide a 45-degree shear wave axially in the sheathing to detect transverse defects, but this would have required double scanning and twice the time or the use of spiral scanning for both type defects. The latter approach has been previously used at ANC for unirradiated fuel rod scanning.

The PEC system hardware is described briefly in Section IV. Additional details are presented in Reference 9. The results of PEC scanning and the corroborative metallography are presented in Section V. In Section VI, limitations of the PEC technique and limitations of the ANC equipment design are discussed.

It should be emphasized that, throughout this report, the term "defect" is used to describe any abnormality in the cladding surfaces and does not imply any loss of cladding integrity. Included as "defects" are scratches, grooves, wear marks, adherent corrosion products, subsurface hydriding, etc. 


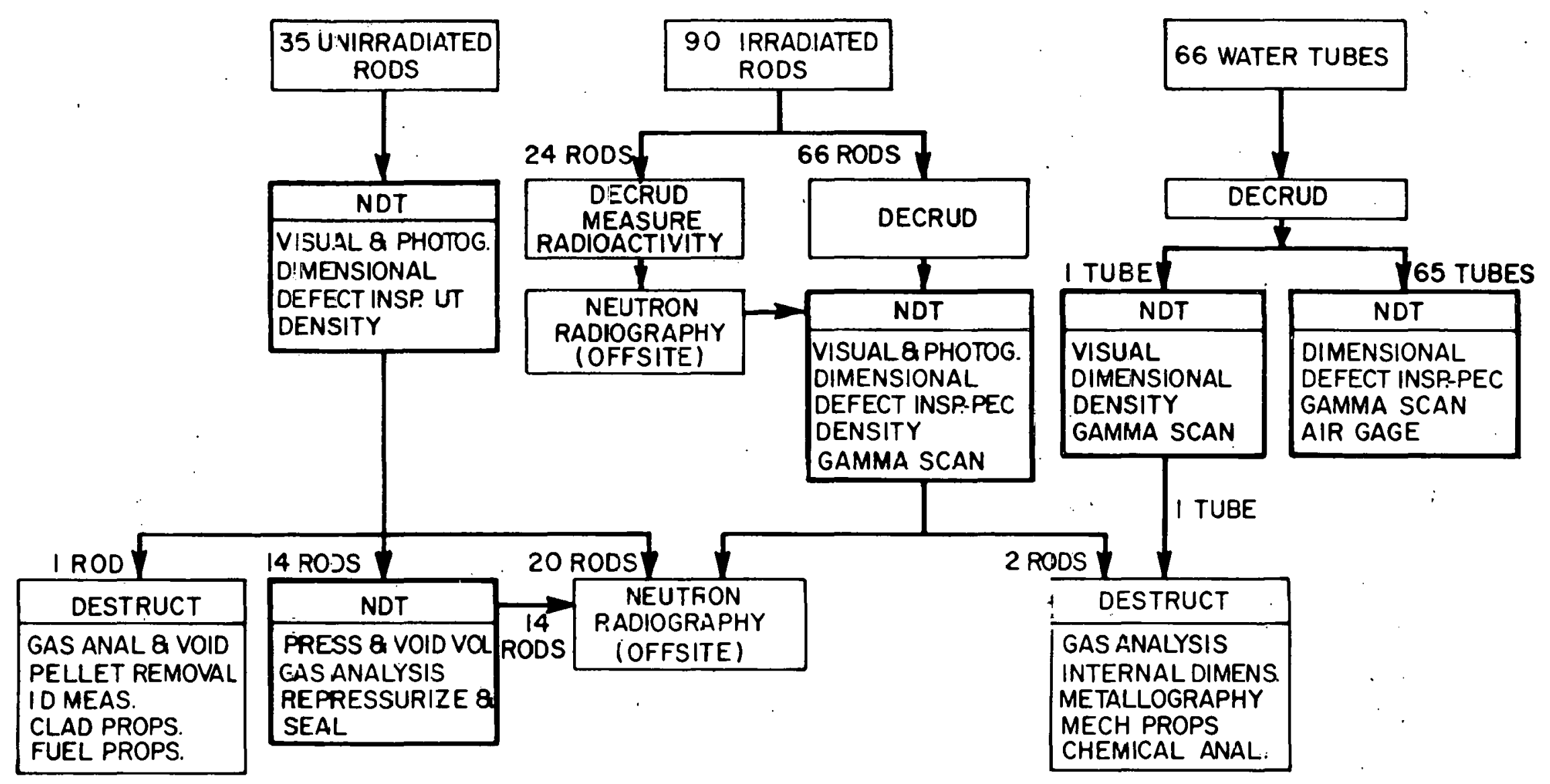

Fig. 2 Fuel roc characterization flow chart. 


\section{SUMMARY AND CONCLUSIONS}

The PEC method has proved to be an excellent technique for nondestructive examination of irradiated fuel rods. The contribution of the PEC examination to the overall fuel rod characterization program is substantial since it provides important information on mechanical condition for fuel rods from which a selection of test rods for IE testing can be made.

With few exceptions, the cladding examined was relatively free of any large defects which might interfere with the IE tests.

Unfueled zircaloy tubes irradiated in the same environment as fueled tubes show appreciably less damage, emphasizing, as may be expected, the added damage associated with the mechanical, chemical, and thermal effects of fuel rod irradiation.

Defect indications observed by PEC were resolved to be primarily small grid wear marks and corrosion on the outer surface. Bowing of some rods and water tubes was quite pronounced, in some cases exceeding 0.020 inch peak-to-peak. Cladding thickness variations noted were small, less than 0.001 inch for most of the tubes; a few fuel rods had up to 0.003 -inch variation.

Fuel-cladding mechanical and chemical interaction were not observed by the PEC system. It must be noted, however, that suitable standards were not available for this type of calibration. 


\section{III. $\cdot$ RECOMMENDATIONS}

As a result of experience gained to date in using the pulsed eddy current scanning system, a number of recommendations can be made. These are summarized below and are discussed more fully in Section VI.

(1) The equipment and techniques should be upgraded to take full advantage of the diametral and length measuring capabilities.

(2) The strip chart recording system should be replaced with a magnetic tape system. Then, computer programs should be developed to speed the data reduction.

(3) The equipment must be mechanically modified to permit the inspection of the heavily instrumented fiel rods to be used in the tcst programs.

(4) It would be highly desirable to develop a new traversing mechanism to handle longer fuel rods. This would permit cxamination of rods from the LOFT reactor or commercial LWRs. 


\section{EXPERIMENTAL EQUIPMENT AND PROCEDURES}

\section{DESCRIPTION OF EQUIPMENT}

The operating principle of the PEC inspection system is similar to conventional eddy current testing. The data analyses in the calculation of field strengths and the transducer design are complicated by the use of pulsed driving currents, but the advantages of the pulsed system greatly outweigh these additional problems.

In theory at least, the wide band signal of the pulsed system permits extraction of all possible information from the test specimens by eddy currents. The high peak energy but low duty cycle permits design of components, especially the sensors, having a degree of resolution and ruggedness not possible in conventional eddy current equipment.

The PEC system which was designed and assembled by the Instrumentation and Measurement Branch consists basically of four major components ${ }^{[9]}$.

The first component is the electro-mechanical scanning fixture (Figure 3) which goes into the hot cell. This unit was designed and built by ANC. After fuel rod testing under off-normal reactor conditions, the rods may be bowed, ballooned, or otherwise distorted. Therefore, in order to keep the sensor coil-to-cladding distance constant, a servo-mechanism (Figure 4) was designed which automatically positions the PEC sensor coil laterally. This servo-mechanism uses two opposing linear variable differential transformers (LVDTs) as sensors. In addition to providing input to the servo-mechanism, the LVDTs also produce information on the rod diameter and extent of bowing. The fuel rod is scanned in the vertical position with the sensors being moved past the rod.

The second item comprises the PEC sensors (Figure 5) made by ANL. These coils must match the electronics package and are specially made for each fuel rod design that is to be inspected.

The top sensor measures the thickness of the zircaloy cladding, and the lower sensor contains two coils to detect inner and outer surface defects in the cladding. The axial and azimuthal orientation of the sensors and LVDTs is illustrated in Figure 6.

The electronics package is the third component (Figure 7). The rack-mounted electronics furnish the power and control for the scanner axial drive and rotational movements, pulse power for the sensors, and signal processing for the data presentation.

Lastly, a six-channel Brush 260 recording oscillograph (Figure 7) provides the readout of the data. 




Fig. 3 Pulsed Eddy Current (PEC) electro-mechanical scanner. 


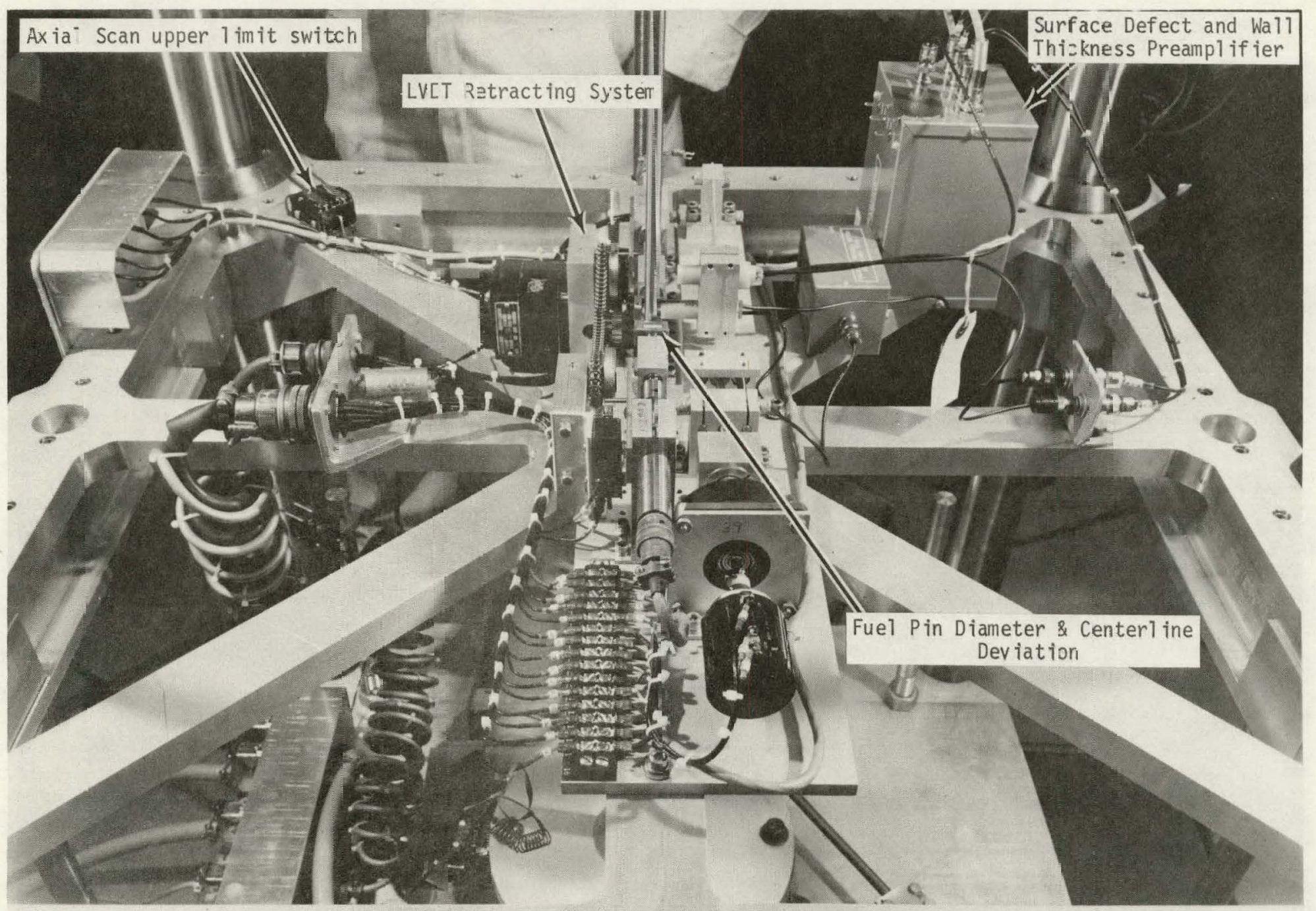




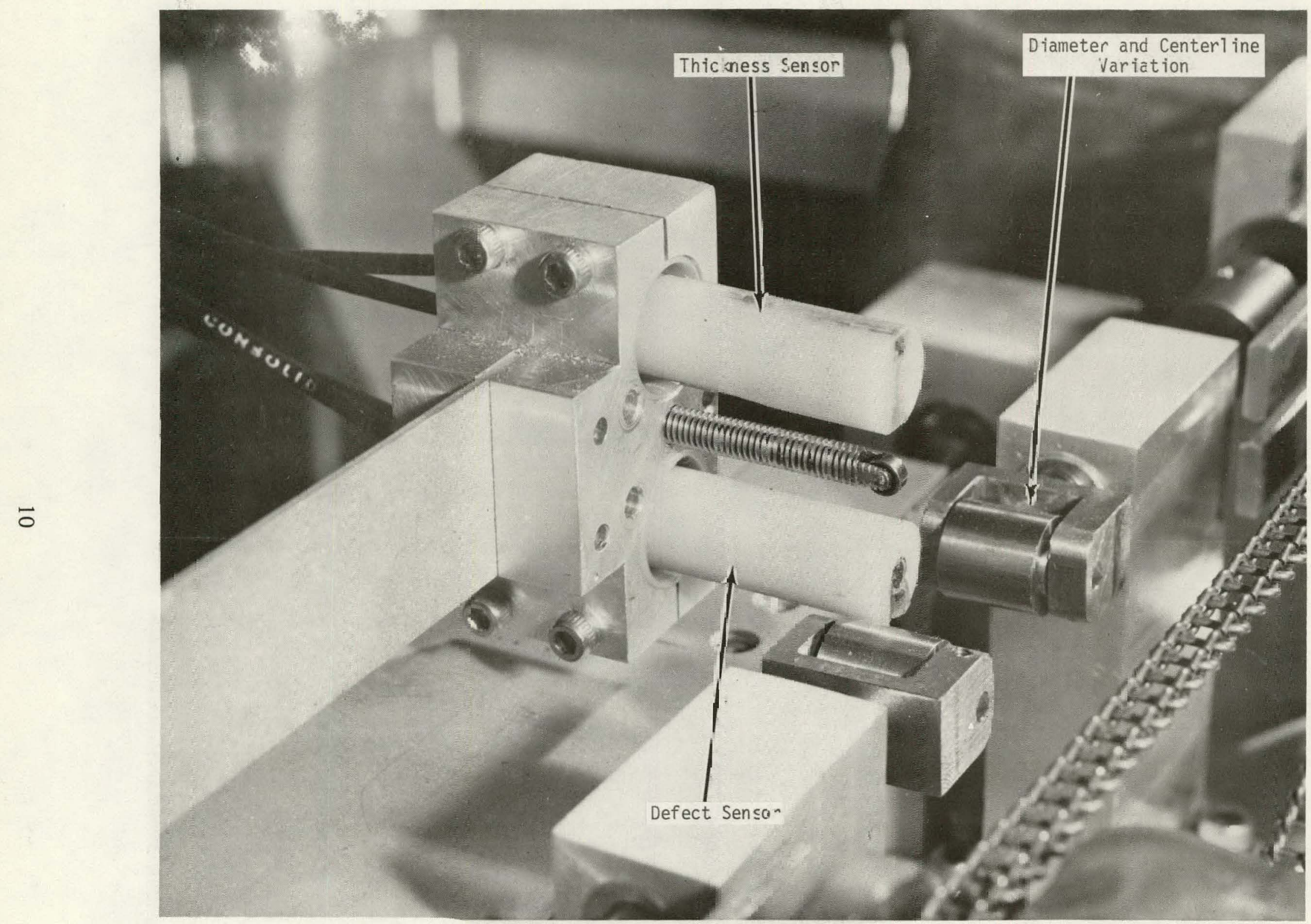

Fig. 5 PEC sensors tor $1 \mathrm{~W}$ ana uv weiect ir sfectio 1 and thbe thickness measurament. 

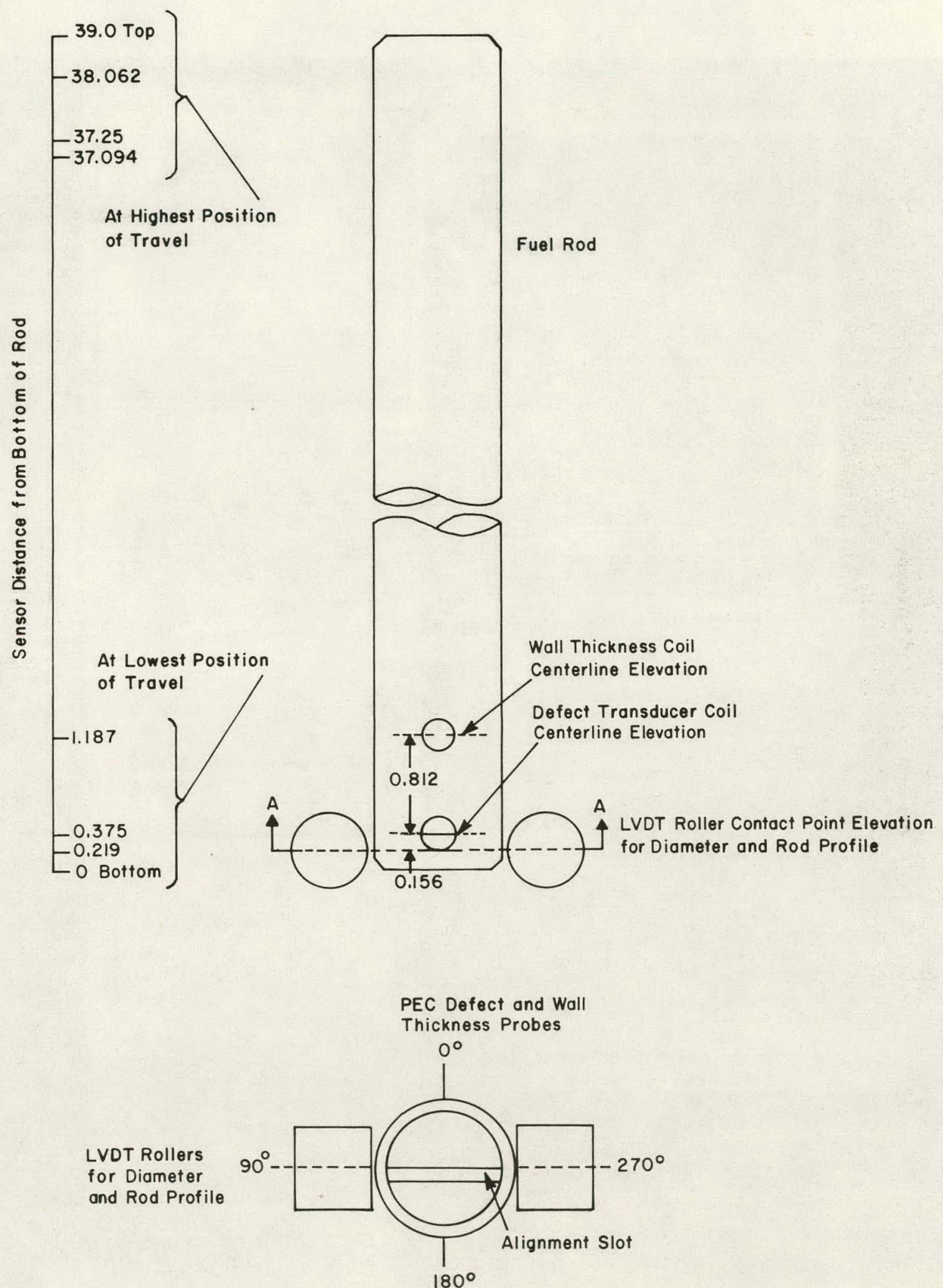

A - A

ANC-A- 4829

Fig. 6 Axial and azimuthal orientation of PEC sensors (all linear dimensions in inches). 


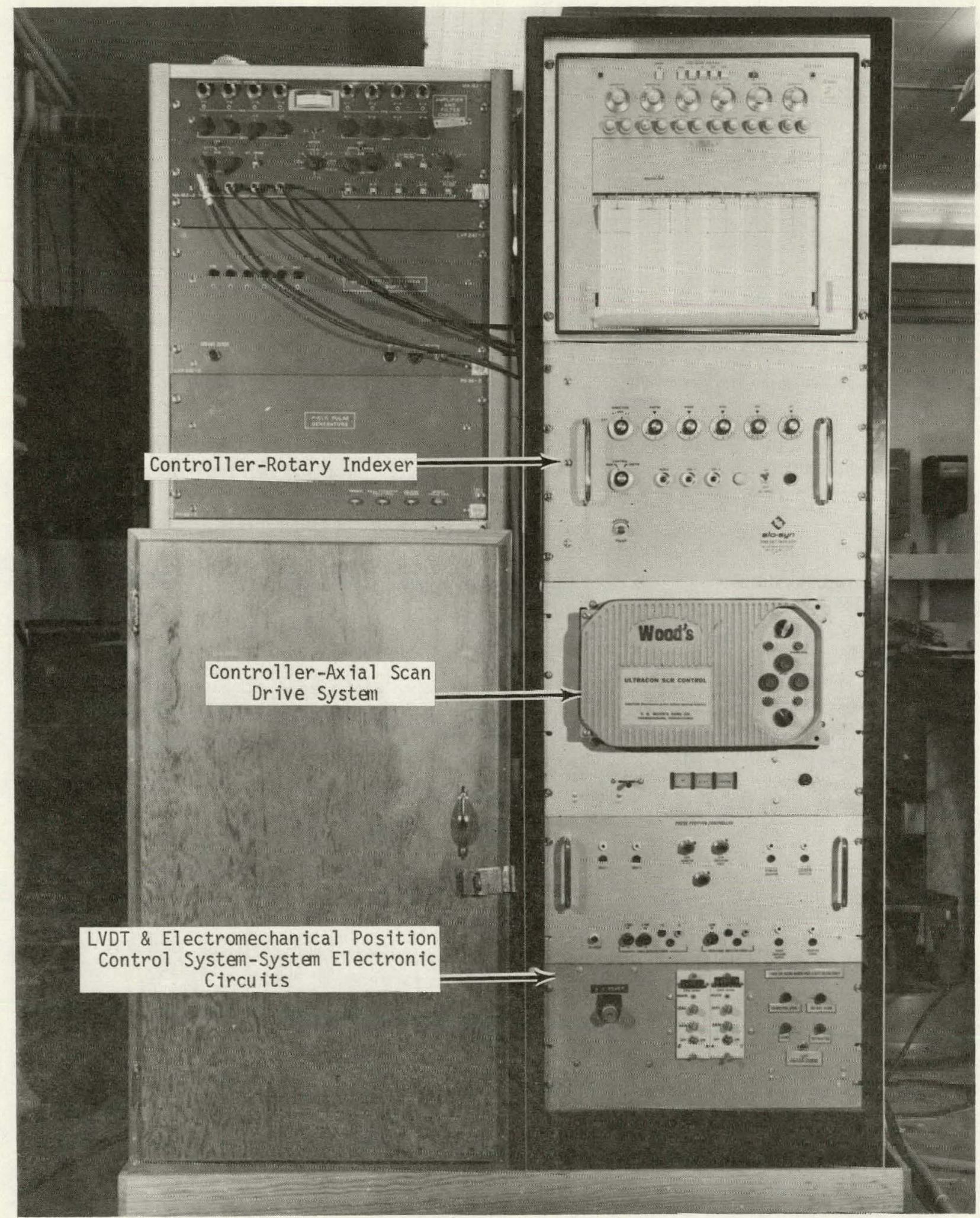

Fig. 7 PEC control console and recorder. 


\subsection{Calibration}

As for other NDT methods, PEC inspection technique is strongly dependent on accurate calibrating standards. Considerable care was therefore employed in fabricating standard specimens for thickness correlation, fuel rod straightness, and for ID and OD defect calibration.

Scanning of the fuel rods and tubes also indicated the need for an additional standard which could correlate variations in diameter. A standard was quickly prepared and is discussed later in this report. Preparation of a more sophisticated, precision-ground standard with increased diametral accuracy is planned.

1.1.1 Wall Thickness Calibration Standard. When the PEC equipment at ANC became operable, some of the first measurements were made on the cladding thickness to compare with the measurements made on unirradiated fuel rods by ultrasonic techniques. A calibrating standard was prepared using Saxton-type zircaloy tubing of nominal 0.391 inch OD, machined internally to provide nominal 0.020-, 0.022-, 0.024-inch-thickness standards. The actual values obtained $(0.021-, 0.022-$, and 0.0239 -inch-wall) and the assembly of the calibrating section are shown in Figure 8. The thickness taper indicated in the figure was readily observed in the PEC scan, as shown in Figure 9, and complicated assignment of absolute values in fuel rod scanning. Variations in thickness over the fuel rod length, however, were easily detected.

1.1.2 Fuel Rod Straightness Standard. A calibrating rod for straightness was fabricated from Invar 36 stock which was rough machined, normalized in controlled atmosphere, hard-chrome-plated, and finish-ground. Measurements made in the INEL Standards Laboratory on the finished standard rod are shown in Figure 10 for four orientations of the rod. The maximum centerline deviation measured by the INEL Standards Laboratory is 0.0053 inch, but in two of the scanning orientations the maximum bow is less than 0.0005 inch.

In addition to locating and measuring variations in rod straightness (bowing), it was also desired to determine bulging or collapse of the fuel rod cladding. By the use of opposing LVDTs, this measurement is readily made. Originally the sensitivity was set at about 0.0023 inch per minor chart division and most of the rods were scanned with this setting. However, as the true capabilities of the equipment were realized, the sensitivity was subsequently increased by approximately a factor of ten to 0.00024 inch per minor chart division in order to detect small variations in fuel rod diameter such as ridging and pitting.

1.1.3 Fuel Rod Defect Standard. Three standards were fabricated from six-inch lengths of 0.391 inch diameter zircaloy cladding taken from an unirradiated Saxton fuel rod. These standards contained 0.100 -inch-long by 0.006 -inch-wide longitudinal and transverse notches on both OD and ID surfaces. Notch depths were nominally $0.002,0.004$, and 0.006 inch. The notches were prepared by EDM (electrical discharge machining) techniques and the dimensions were certified by means of replication with GE RTV liquid silicone rubber. The results of scanning the standards are presented in 


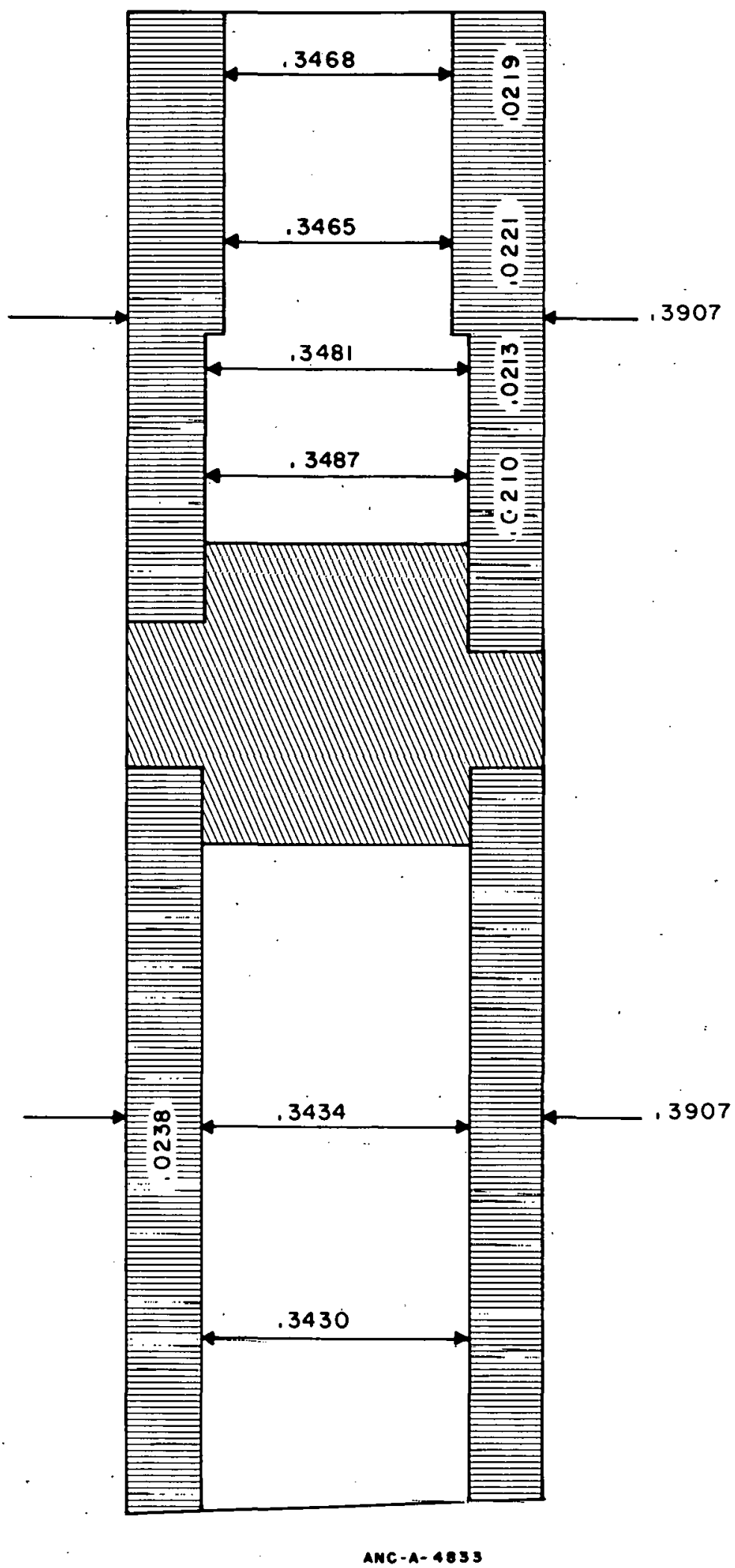

Fig. 8 Calibrating standard for cladding thickness (all dimensions in inches). 

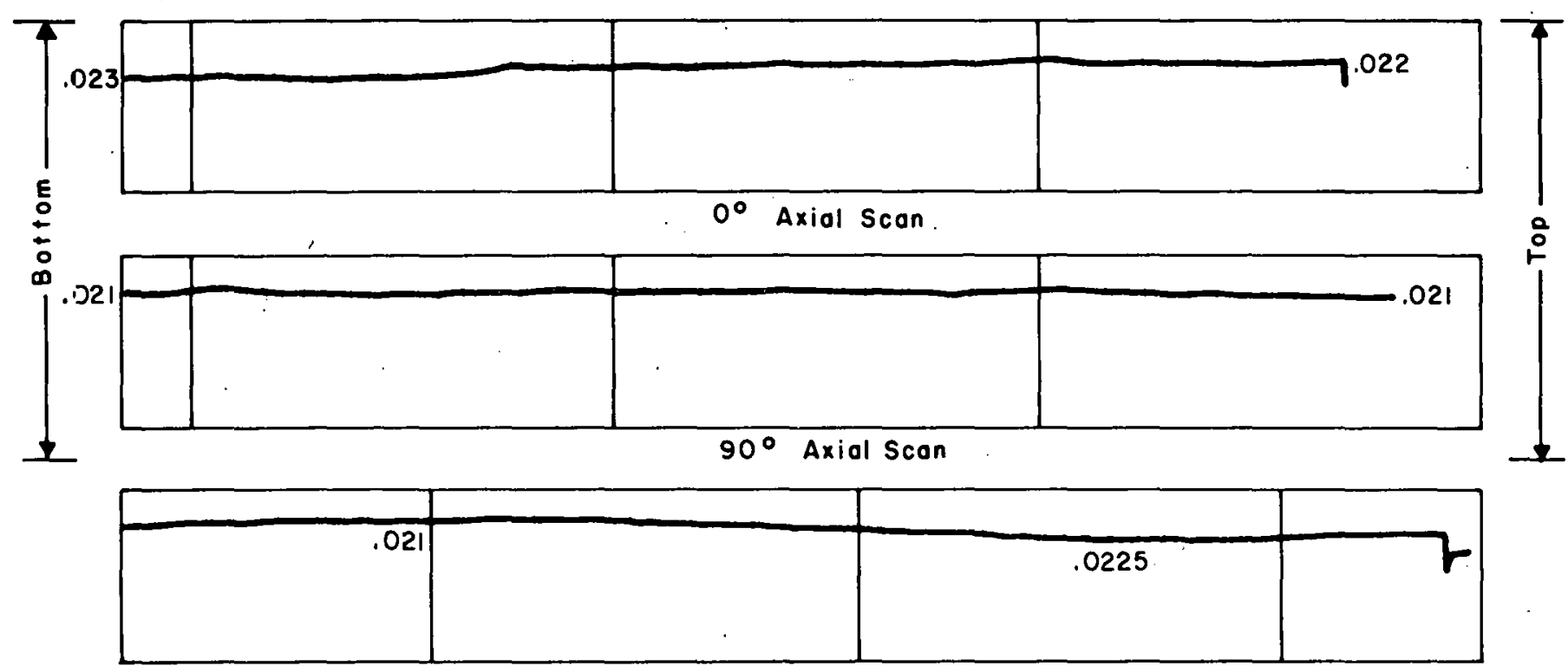

$360^{\circ}$ Rotation af Boffom of Rod

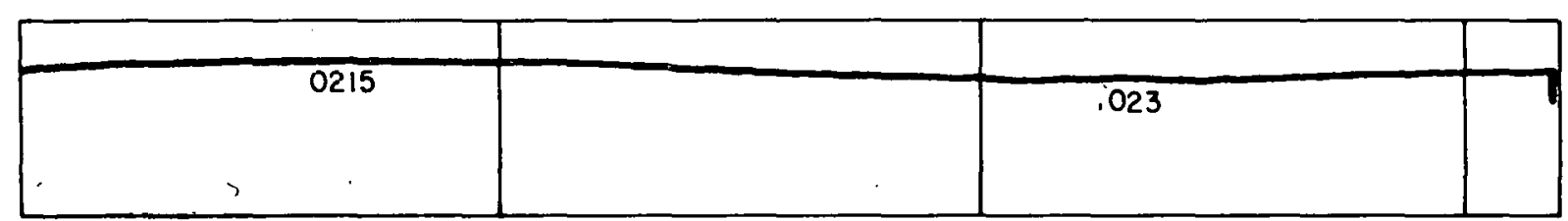

$360^{\circ}$ Rotation af Top of Rod

$A N C-A-4835$

Fig. 9. PEC thickness scans showing end-toend circumferential variations in a typical fuel rod cladding (all dimensions in inches). 


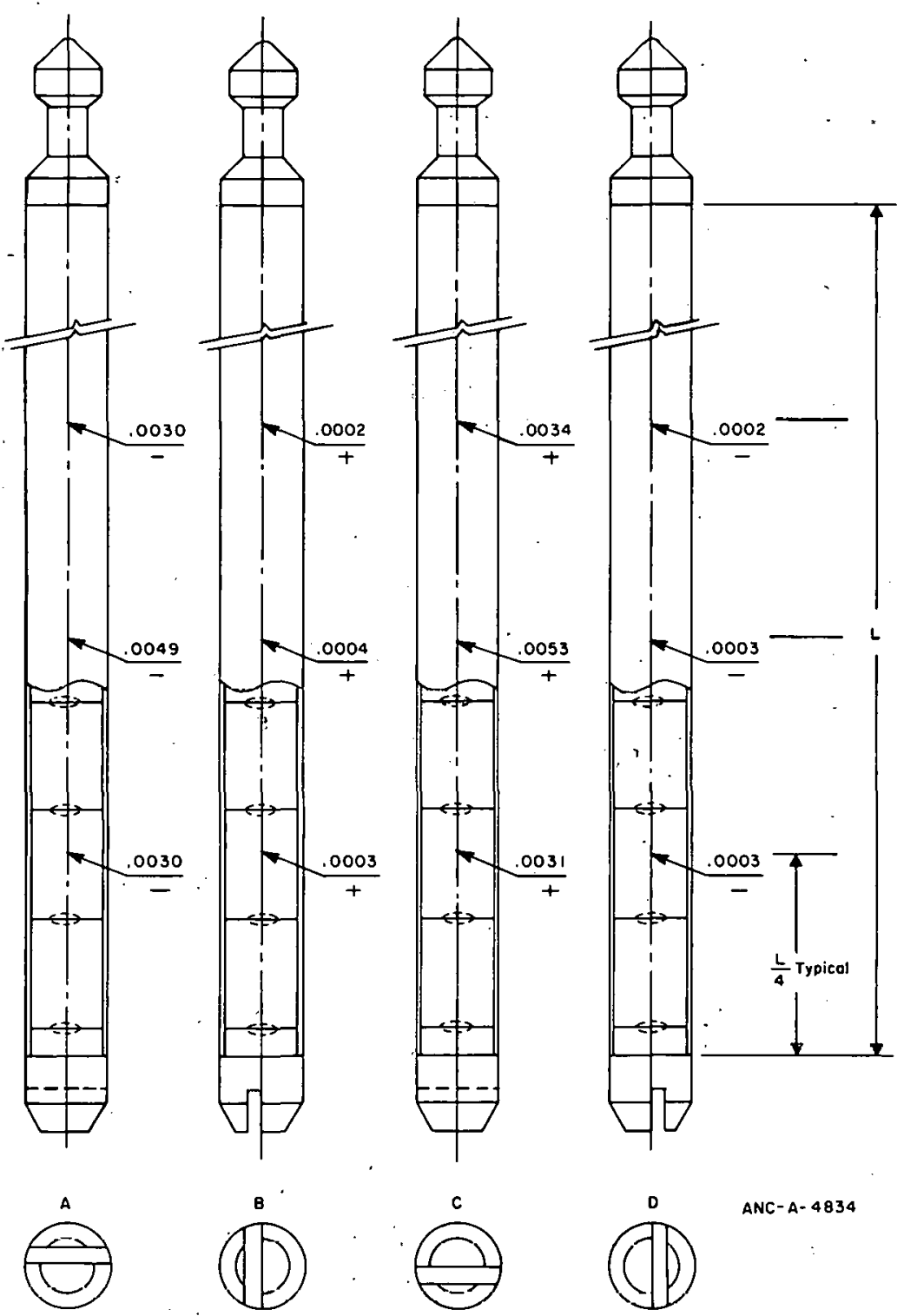

NOTE: + means sample bow is up and away from plane of paper, toward viewer;

- means sample bow is down and into the plane of paper, away from viewer.

Example: at center, maximum TIR is $0.0049+0.0053=0.0102$.

Fig. 10 Fuel rod straightness standard (all dimensions in inches). 
Figures 11 and 12. The defect indications are much stronger for longitudinal than for transverse defects. Moreover, the OD defects produce stronger indications on the PEC system than do the ID defects.

\section{TEST PROCEDURE}

The PEC scanning equipment was operated in accordance with the procedures set forth in the Operating Manual prepared by the ANC Instrumentation and Measurement Branch. These procedures are briefly summarized in the appendix to this report. Normal procedure required scanning of the calibrating standards each day before inspecting the irradiated rods or water tubes. In addition, frequent scans of the calibrating standards were interspersed throughout the fuel rod inspections.

Thirty-four irradiated fuel rods and sixty-six water tubes were examined remotely using the PEC inspection equipment. Thirty-seven chart scans (the 0 and 360-degree were deliberate replications), each with six traces, were obtained for each fuel rod and water tube. The entire examination, including limited destructive examination for correlation, required nearly two months.

Each fuel rod scan and each water tube scan was examined in detail by personnel from either ANC's Materials Technology Branch or Quality Division who were qualified to ASNT's TC-1A Level III ${ }^{[7]}$. The scans from each rod or tube were further reduced to the chart form illustrated in Figure 13. These charts provide a simple visual presentation of the location, extent, and size of the indications observed in the PEC scanning. A quick reference on the same chart is also available for cladding thickness, straightness, and diameter variations.

To further evaluate and confirm the defect indications shown by the PEC system, two fuel rods and one water tube were selected for destructive examination and metallography. The results are presented in Section V. 

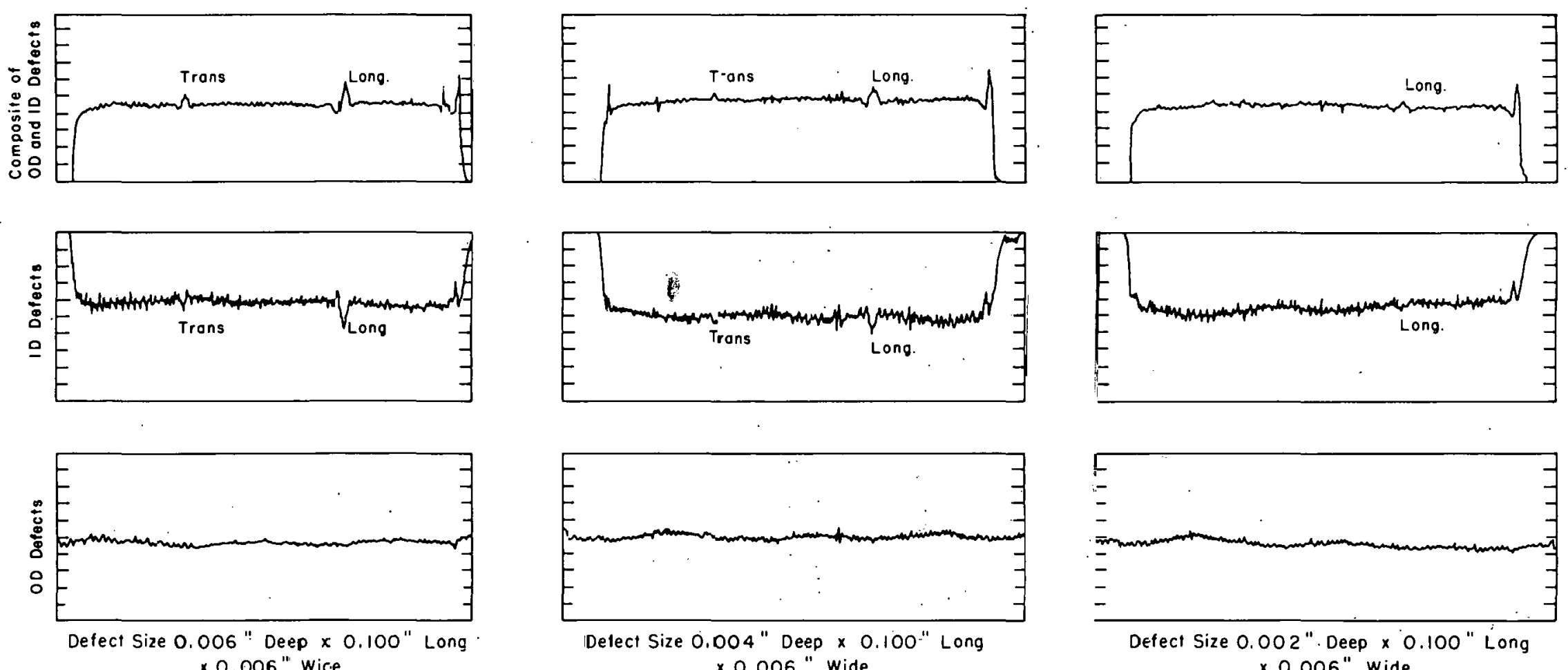

Detect Size $0.004 "$ Deep $\times 0.100^{\prime \prime}$ Long

$\times 0.006 "$ Wide

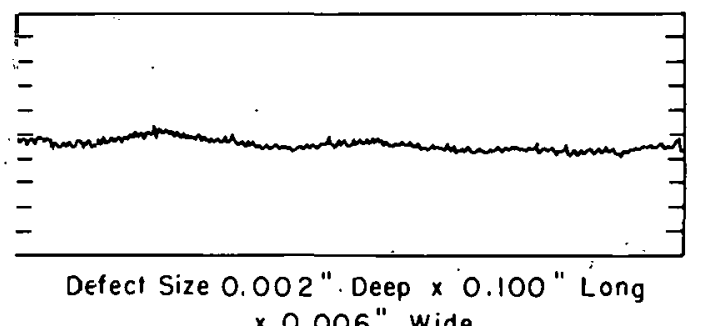

$\times 0.006 "$ wide

ANC-B- 4934

Fig. 11 Scan of PEC cäibration rod for surface defects and clid thickness-230-degree orientation for ID dəfects (all dimensions' in inches). 

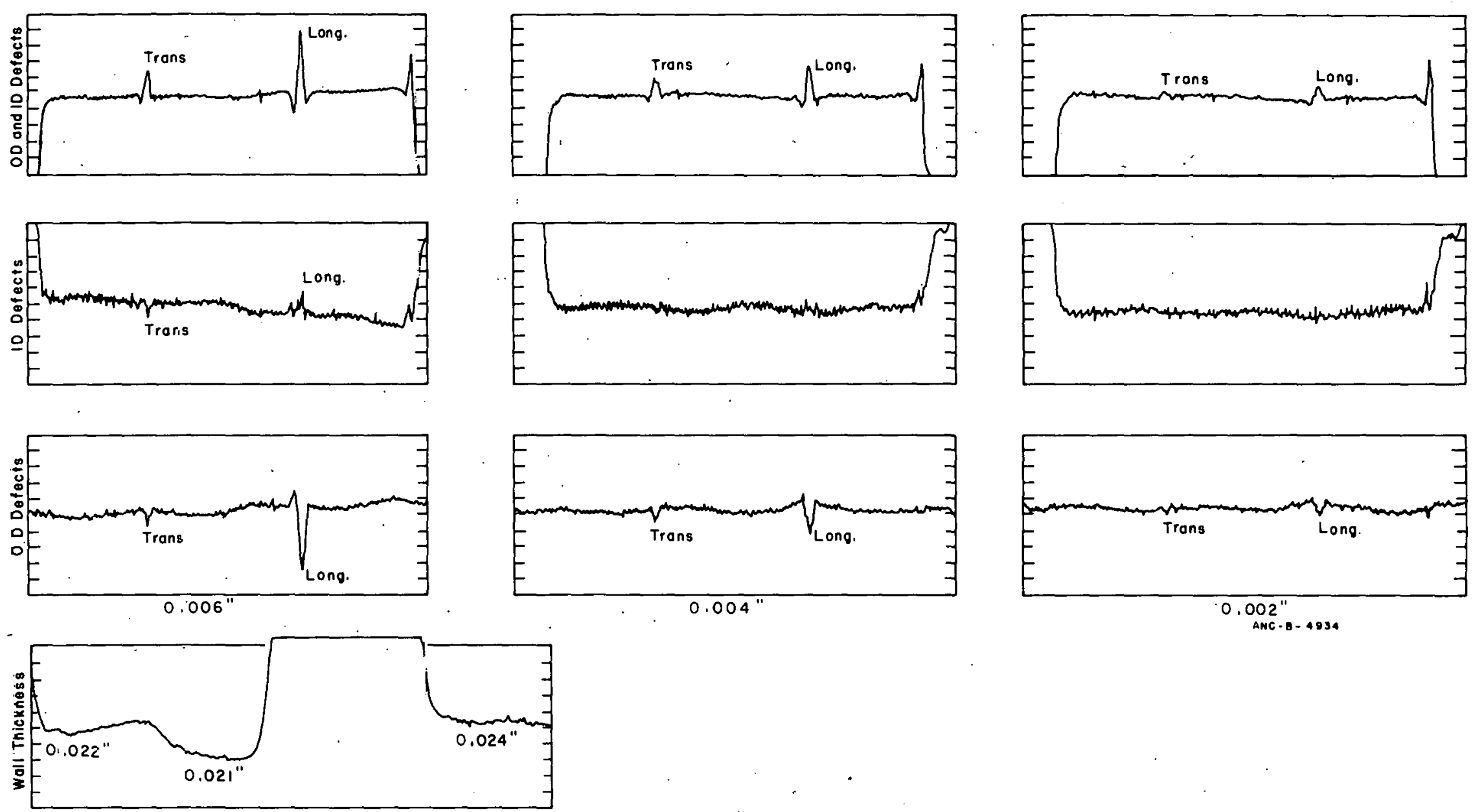

.002

AMC. - - 4934

Fig. 12 Scan of PEC calibration rod for surface defects and clad thickness-50-degree orientation for OD defects (all dimensions in inches) 
ANGULAR POSITION (DEGREES)

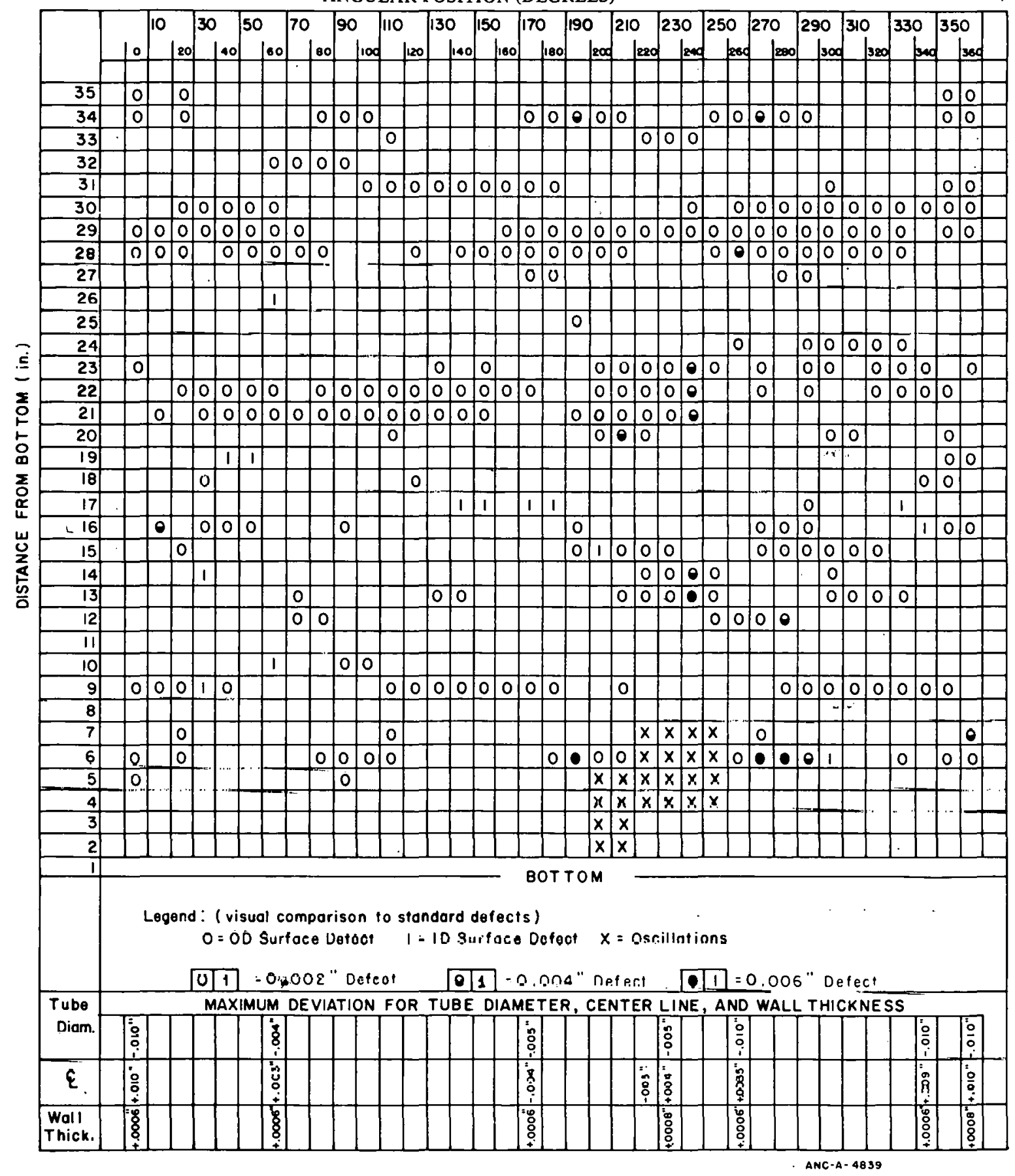

Fig. 13 Simplified defect chart of load-follow fuel rod 864 . 


\section{TEST RESULTS}

\section{GENERAL}

From Figures 11 and 12, it can be seen that the PEC instrument is more sensitive to longitudinal defects tiran to transverse defects and that both types of defects are more readily observed on the outer surface than on the inner surface. The 0.002 -inch-deep defects in both longitudinal and transverse directions can be readily observed on the outer surface of the standard but only the longitudinal defect of this size can be detected on the inner surface of the standard.

The volume of data generated from a complete PEC scan of a single rod (37 charts, containing 6 traces each) makes correlation of data difficult and an overview of defect patterns more so. In order to circumvent these problems, a three-dimensional mapping technique was attempted. The length and angular displacements of the scans defined a plane, and the relative magnitude of the indication defined a point above or below the. plane. This approach was used to generate the pseudo-maps shown in Figures 14-16. Using Figure 14 as an example, it is readily apparent that the major OD defects frequently appear in four adjacent scans (i.e., an arc of 40 degrees) located approximately 90 degrees apart. When the centerline locations of the four spacer grids are superimposed, a correlation is seen which indicates wear as a possible cause for these defect indications. The possibility is shown more graphically in Figure 15. In this case, the wear marks associated with the paired wear pads on the spacer grid are readily identifiable in at least two positions. A pair of wear pads is located in each of two positions, 90 degrees apart, for each spacer grid. A loading spring is located diametrically opposite each pair of wear pads. In the case of the lowermost grid, the pseudo-map for water tube No. 5 (Figure 15) shows that the pairs of pads were initially in contact at 160 and 250 degrees, and that at some time the rod was rotated approximately 20 degrees, bringing the wear pads to 180 and 270 degrees for the balance of the rod's exposure (or vice versa).

One peculiarity in the combination of the PEC characteristics and the mapping technique should not be overlooked. The circumferential extent of defects can be estimated from the recurrence of the indication at the same position on adjacent scans. At this time, no similar capability exists to estimate longitudinal extent. While circumferential defects may appear as ridges on the pseudo-map, longitudinal defects will appear only as spikes.

\section{ROD EXAMINATION}

\section{$2.1 \quad$ Fuel Rods}

The Saxton fuel rods examined were two basic types with some design variations within each type. The twenty-two load-follow rods (identified by 800 -series numbers) represented the highest levels of burnup (approximately 15,000 to $18,000 \mathrm{MWd} / \mathrm{T}$ ). Enrichinents, internal gas composition, and gas pressure varied within this group. Other fuel 


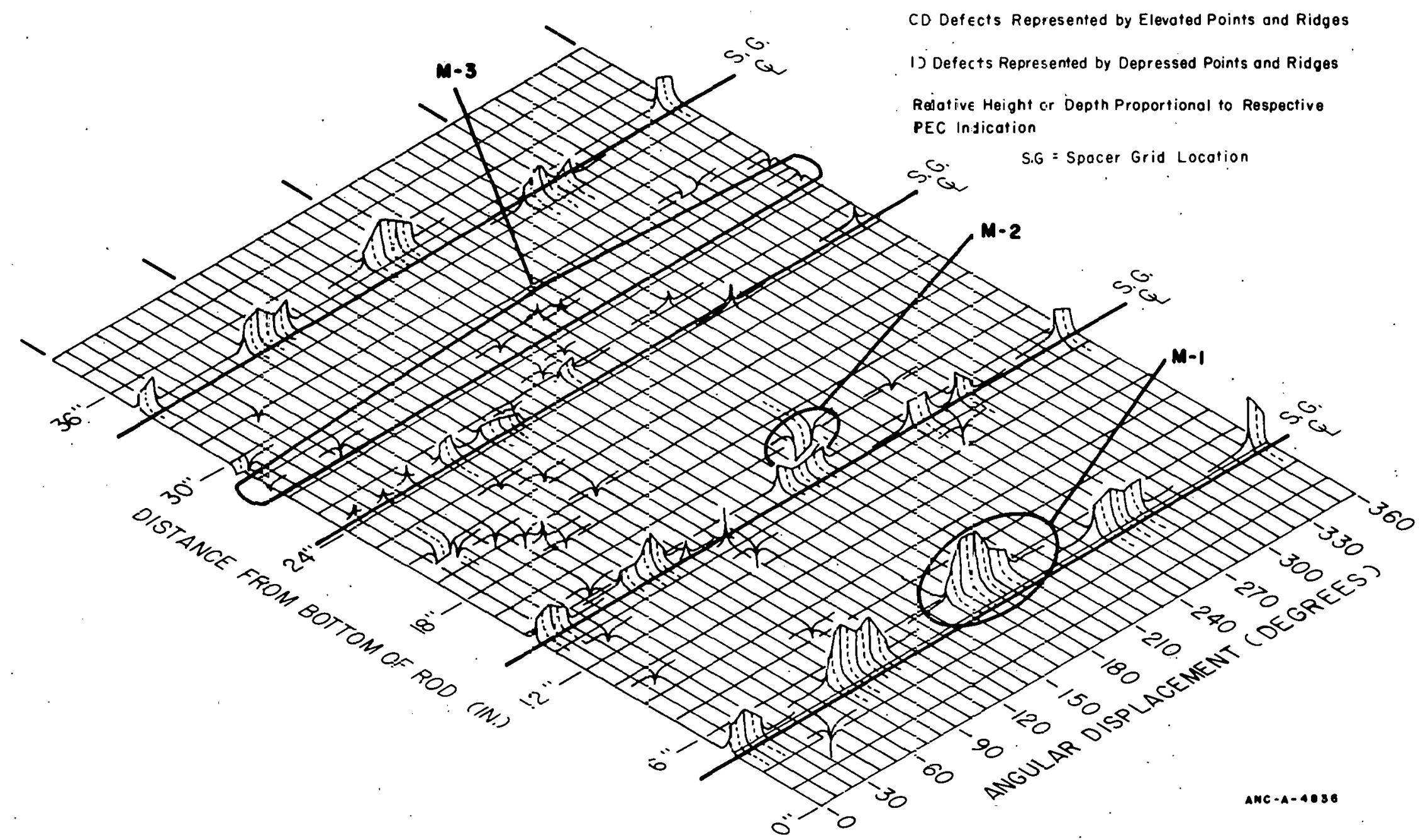

F,g. 14 Pseudo nap of water tube STD-50. 
OD Defects Represented by Elevated Points and Ridges

ID Defects Represented by Depressed Points and Ridges

Relotive Height or Depth Proportional

to Respective PEC Indication

S. G. = Spacer Grid Location

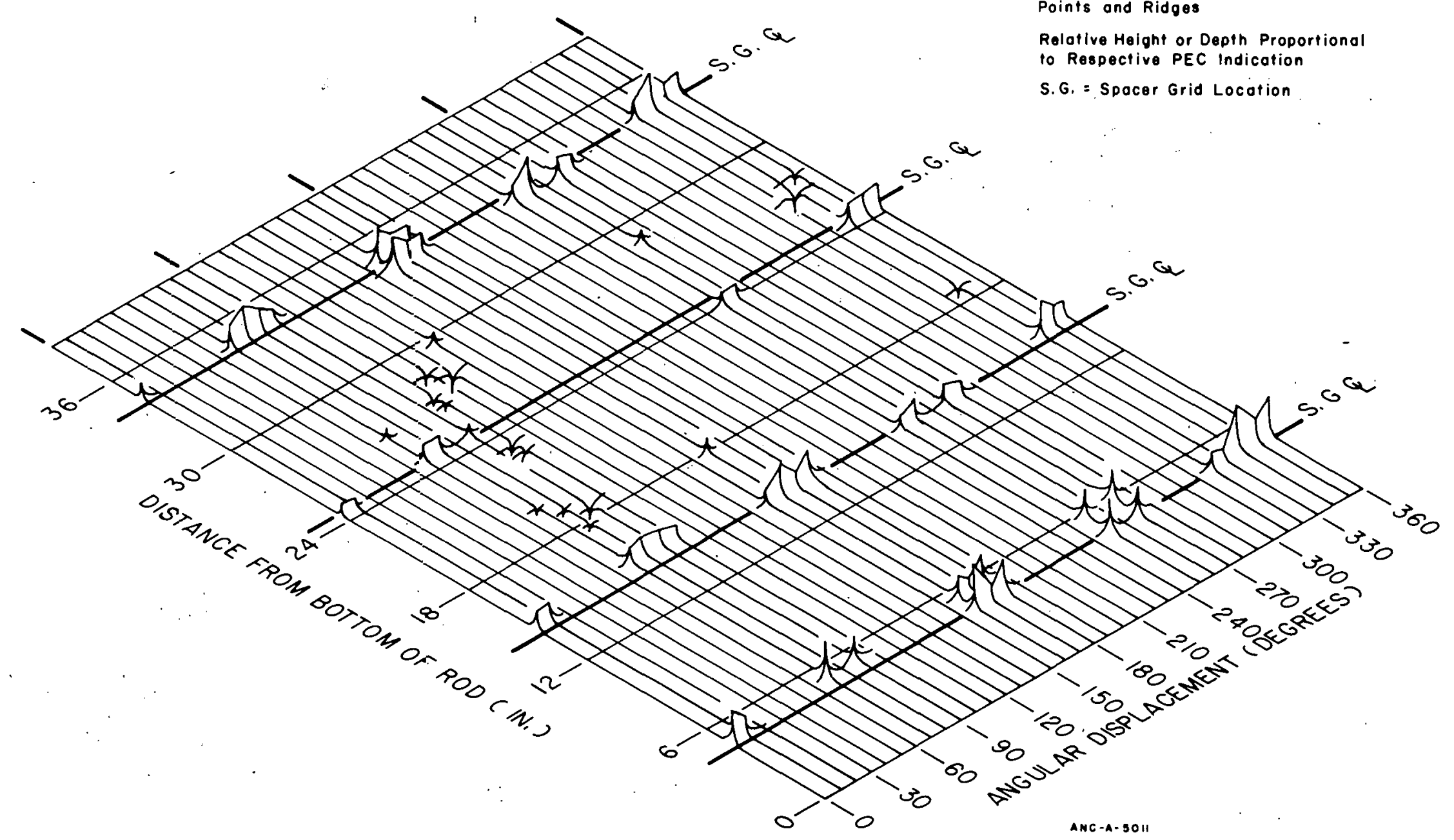

Fig. 15 Pseudo map of water tube No. 5. 


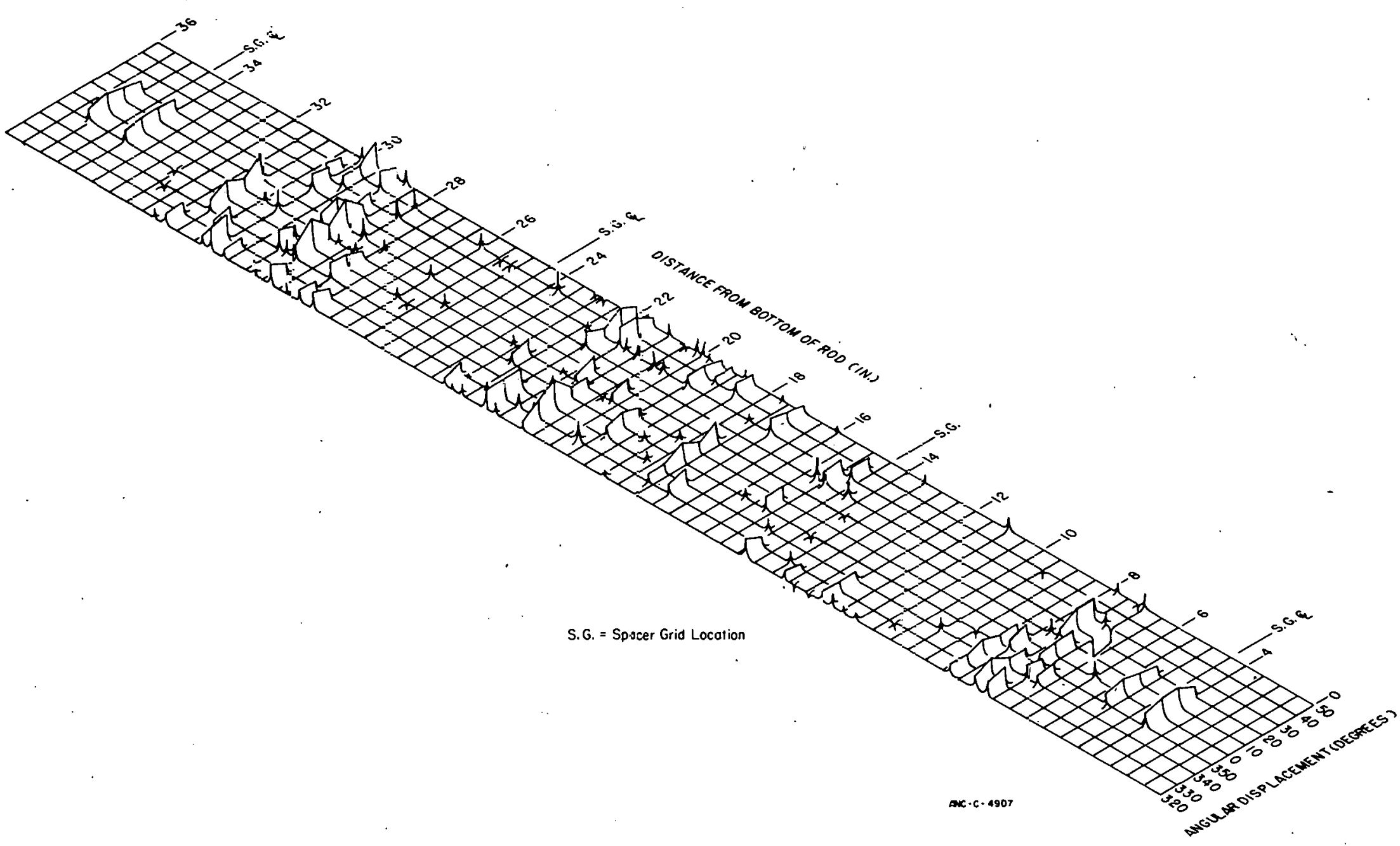

Fig. 16 Partial pseucio map of load-follow fuel rod 864. 
rods carrying M-series designations had been fabricated in Japan by MAPI ${ }^{[a]}$ and irradiated in Saxton at a lower power level to a burnup of about 6,000 MWd/T. A detailed description of the rods and the irradiation conditions is presented in Reference 8 .

Defect indications were found mostly on the outer surface of the load-follow rods. Only a few small scattered ID defect indications were observed. Only six rods had ID defect indications extending 30 degrees in width and only two of these rods $(858,865)$ had defects extending 40 degrees in width.

Many of the 800-series fuel rods gave PEC indications which were scattered over the major portion of the outer surface of the rod and which could frequently be correlated with corrosion product deposits or surface roughness on the OD. Some of these indications were of large size (compared with the 0.006-inch-deep standard). Cladding thickness variations of 0.001 inch were observed. Centerline variations on many of these rods were \pm 0.004 inch or less but on some, bowing of \pm 0.010 inch was measured. Many rods had diametral variations of $0.010 \mathrm{inch}$. Diameter variations were generally negative and probably resulted from inward creep of the cladding.

The MAPI fuel rods were relatively free of defect indications. For comparison with the 800 -series rods, a typical chart of an M-series rod is shown in Figure 17. The indications observed on these rods were primarily on the OD surface. Only four M-series rods had any ID defect indications and these were usually near the top of the rod. Cladding thickness variations were similar to those found on the 800 -series rods except for two rods (M48 and M52) which had \pm 0.006 -inch variations. Diametral variations were normally 0.0004 inch or less. Centerline (bowing) variations exceeded those in the 800 -series rods. A maximum of \pm 0.012 inch was observed on some rods but most were in the 0.006 to 0.008 inch maximum range. This bowing has probably resulted from the relatively strong flux skewing on this assembly due to its irradiation position at the edge of the Saxton core.

The PEC charts of both M-series and 800-series fuel rods frequently contained signals which were attributed to corrosion-product deposits on the fuel rod surface. This residual deposit remained even after the decrudding step which used a TURCO solution.

Nearly all of the fuel rods and water tubes gave well-defined but small OD defect indications at four axial locations and spaced at 90-degree intervals around the rod at each of the grid spacer axial locations. The axial distances between these indication groupings were approximately 10 inches. These OD defect indications were readily correlated with the grld spacings (Figures 14-20) in the fuel assembly and thus appeared to reflect wear areas on the fuel rod or water tubes from vibration against the grids. When these OD defect indications were subtracted from the total number of indications, most of the fuel rods and water tubes were relatively free of defect indications.

[a] Acronym for Mitsubishi Atomic Power Industries, Japan. 
ANGULAR POSITION (DEGREES)

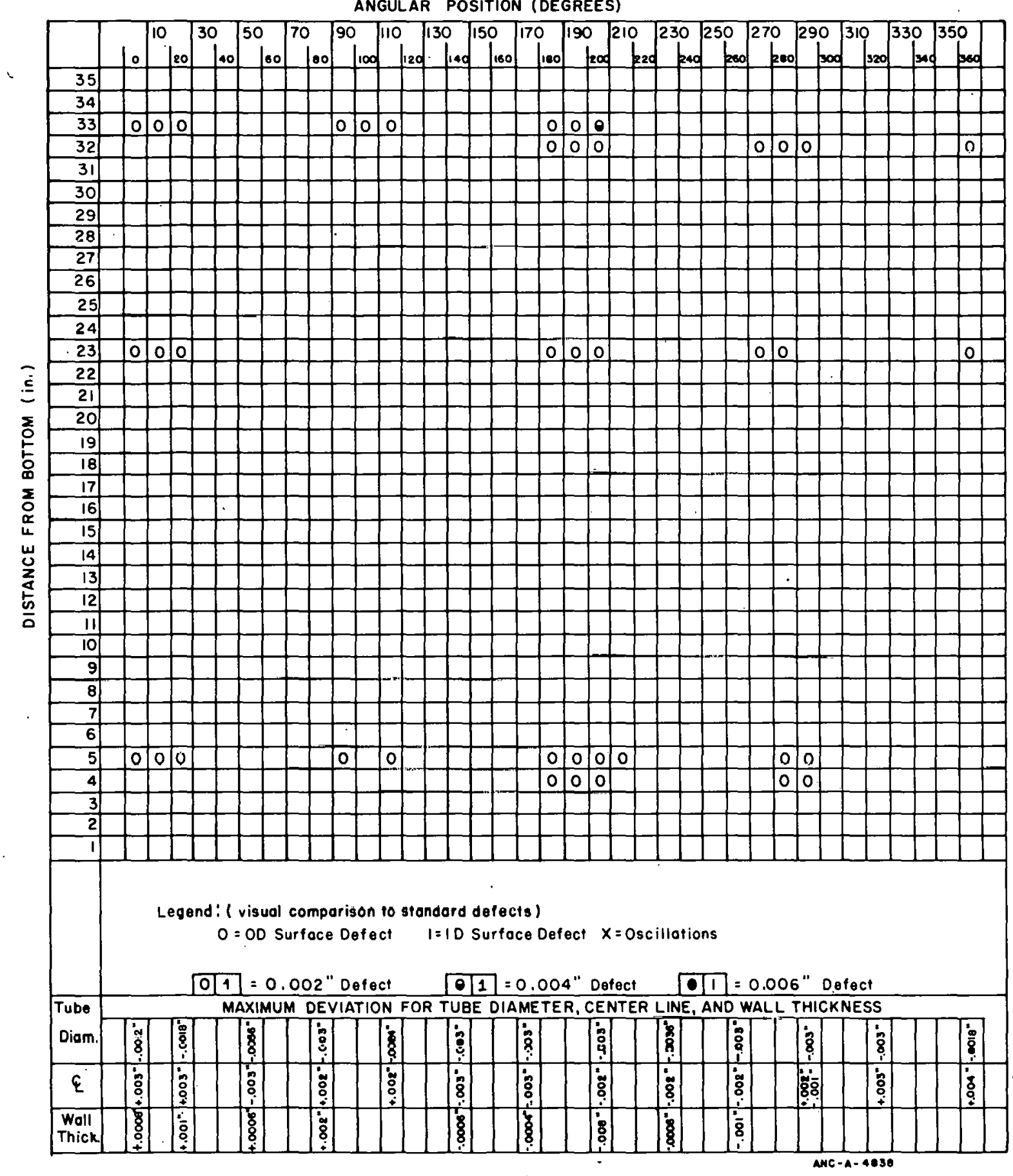

Fig. 17 Simplified defect chart of MAPI fuel rod M22. 
$75-B-20-2$

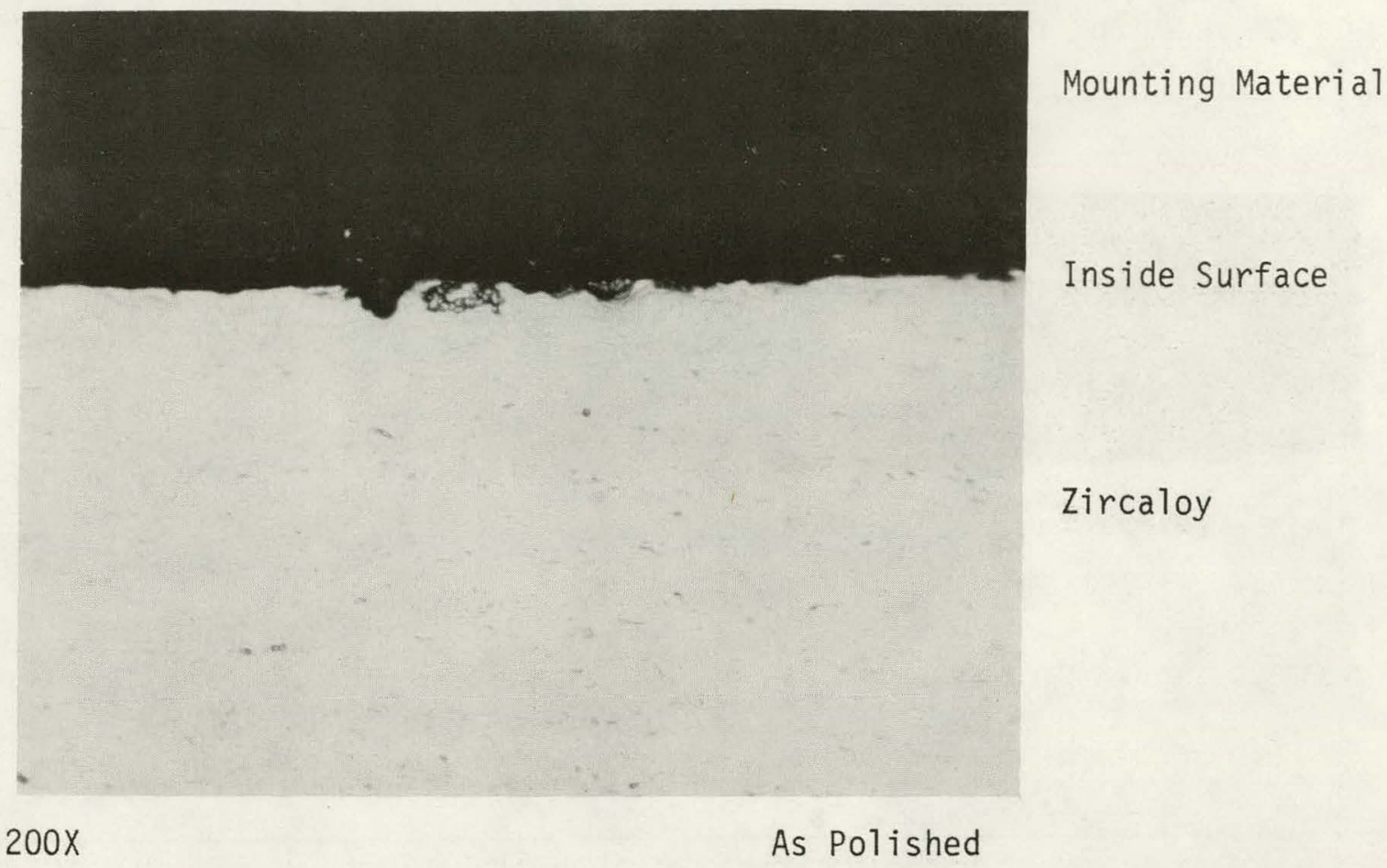

Fig. 18 Micrograph of 0.0008 -inch-deep defect found on inside of water tube STD-50 at 215-degree orientation.

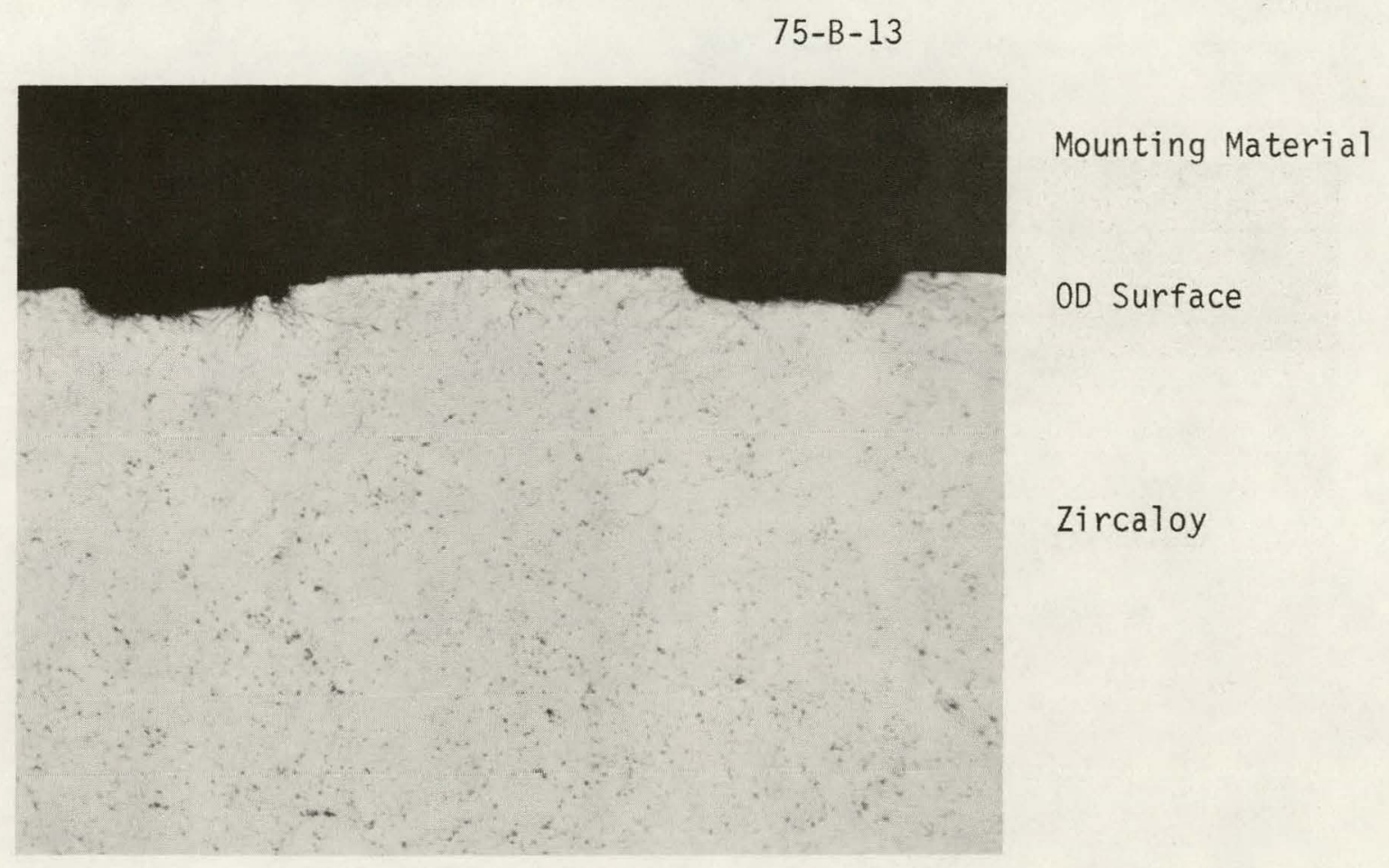

Fig. 19 Micrograph of grooves found on OD of water tube STD-50 in Sample M-3 at 200-degree orientation. 


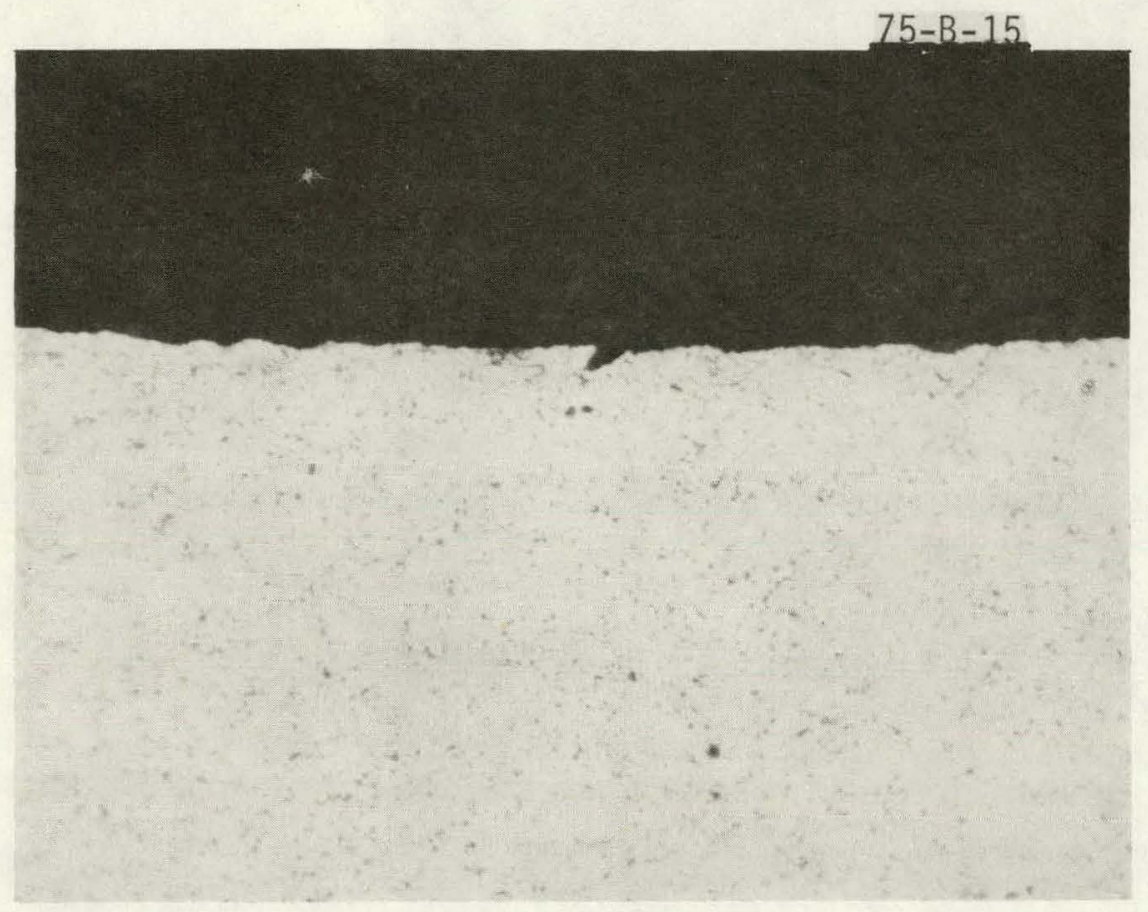

Mounting Material

Inside Surface

Zircaloy

As Polished

\section{5-R-15-?}

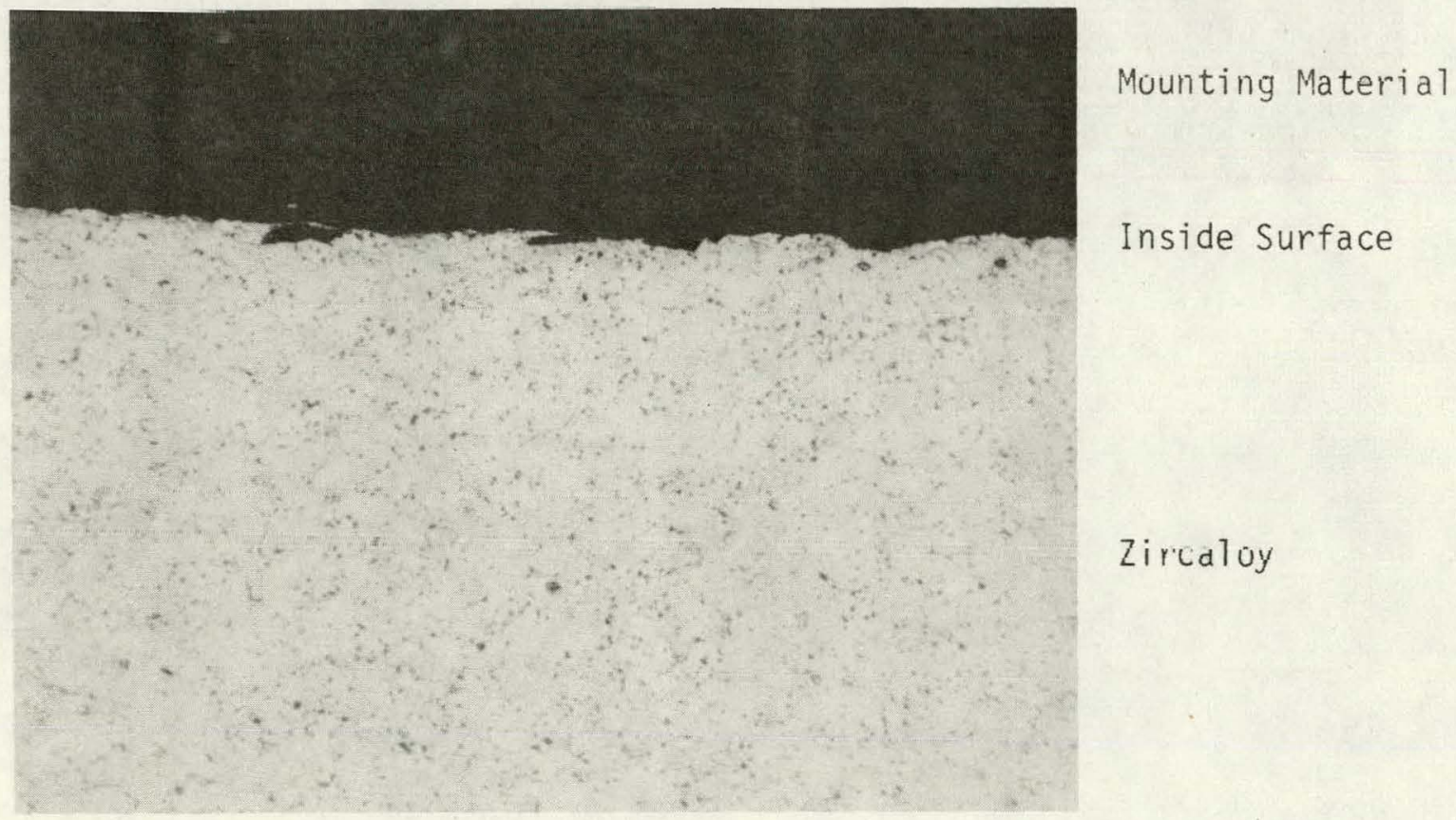

As Polished

Fig. 20 Micrographs of ID defects found in water tube STD-50 in Sample M-3 at 0-degree orientation. 
In the course of the characterization program, ample opportunity was provided to compare the results from the PEC examination with other techniques. Thirty-five unirradiated fuel rods (900-series) were examined by ultrasonic techniques (UT). Details of these examinations are to be reported ${ }^{[8]}$. Generally the UT scans were "clean" in both longitudinal and transverse orientations. UT indications observed on the OD surface were mostly attributed to surface scratches. Rods 924 and 952 were also examined by PEC. Both PEC and UT indicated a surface flaw about halfway along the length of Rod 952. Cladding thickness variation was negligible in both examinations, and this was confirmed by micrometer and bore gage measurements. Absolute value of wall thickness measurement made by PEC correlated well with the micrometer measurements while the UT value was 0.0015 to 0.002 inch higher.

As one would expect, unirradiated fuel Rod 924 was nearly free of PEC defect indications, had a maximum cladding thickness variation of 0.0008 inch, a bowing maximum of 0.005 inch, and essentially no diameter variation (one small region indicated 0.002 inch). However, there were some differences between the PEC and UT defect indications. The PEC scan showed OD defects about 4 inches from the bottom of the rod and no ID defects, whereas the UT scan indicated some defects (visually determined to be surface roughness) extending from the bottom of the rod to mid-length. The transverse mode UT scan provided most of these defect indications; the longitudinal scan was almost clean. Thickness variation measurements using UT and PEC were in excellent agreement (that is, 0.0008 inch) but noise oscillation equivalent to 0.0005 inch made the UT measurement less precise than the PEC. The absolute value of thickness measured by PEC was about 0.0025 inch less than the UT measurement and was in agreement with micrometer measurements made on a similar fuel rod.

On the basis of these observations, it is concluded that the transverse mode of UT examination is more sensitive to transverse defects than the PEC system. There appears to be little difference in the UT longitudinal mode compared with PEC in locating longitudinal defects. It was considerably easier in the PEC examination to separate ID from OD defects. Thickness measurements correlated well. The PEC system provided diameter and centerline data not obtainable from the UT scanning equipment which was used.

\subsection{Water Tubes}

The "water tubes" examined by PEC techniques were, as one might expect, generally in better condition than the fuel rods. The bulk of the OD indications could be related to wear marks from the spacer grid wear pads. Only five tubes gave any ID indications. Average maximum diametral variation was only about $1 / 6$ of that determined on the fuel rods, with more than half of the tubes giving no measurable diametral variation (that is, $<0.0005$ inch). Centerline variations, however, were about comparable to the fuel rods $(0.011$ inch average maximum per tube or rod). Average maximum wall thickness variation for the tubes was about one half that of the fuel rods. For the most part the irradiated tubing appeared to be in very good condition (as determined by the PEC scans), with defects and dimensions being about comparable to the unirradiated fuel rods. 


\section{METALLOGRAPHIC EXAMINATION}

\section{$3.1 \quad$ Fuel Rods}

A typical simplified defect chart of fuel rod 837 is shown in Figure 21. Extensive OD indications were observed over much of the fuel rod surface. Some of these indications were readily associated with wear marks, but in an area extending from about 9 to 17 inches from the bottom of the rod, relatively massive indications covered nearly the entire circumference. For about 140 degrees these indications appeared to have considerable depth $(>0.006$ inch). Although some scattered ID indications were observed, none were significant. Diameter variations on this rod were about average, but centerline and wall thickness variations were among the highest observed on any of the fuel rods examined.

Additional detailed results of the destructive examination performed on this rod will be reported separately ${ }^{[8]}$; only correlation with the PEC' is discussed here.

Cutting locations for fuel rod 837, fuel rod 864, and water tube STD-50 were carefully selected to permit metallographic examination of the areas giving "defect" indications in the PEC scans. These cutting diagrams are illustrated in Figures 22-24.

Four of the five metallography specimens from rod 837 were taken for correlation with the PEC data. These specimens, as with similar specimens from the water tube (STD-50) and the other fuel rod (864) were subjected to repeated polish/examination cycles. Each cycle removed U.U10 to 0.020 inch of material between examinations, for a total depth of 0.400 inch in the case of transverse specimens.

Specimen M-1 was longitudinally uriented and centered approximately 12.4 inches from the bottom of the rod. The "defect" in this case showed up on all the traces, except the ID trace, for scans from 80 to 340 degrees. Wall thickness and diametral variations were also affected. The defect, when located and examined, proved to be a severely corroded area on the fuel rod. Figures 25 and 26 show the affected area and the extent of wall thinning and corrosion product buildup observed.

Specimen M-3, a transverse specimen centered at 1.75 inches, revealed several very small OD scratches (approximately 0.002 inch deep) which are beyond the resolving power of the PEC system, and one OD gronve approximately 0.001 inch deep by 0.004 inch wide in the area of interest (Figure 27).

Transverse specimen M-4 was removed from an area which corresponded to the spacer grid and showed probable indications of wear, with lesser indications in other areas. Examination revealed one of the worn areas (Figure 28) as a flat-bottomed groove approximately 0.0005 inch deep and 0.006 inch wide. The remaining indications appear to have resulted from subsurface hydride, concentrated in the outer 0.003 inch of material (Figure 29). Very shallow grooves were apparent approximately 90 degrees from the location shown in Figure 28. 


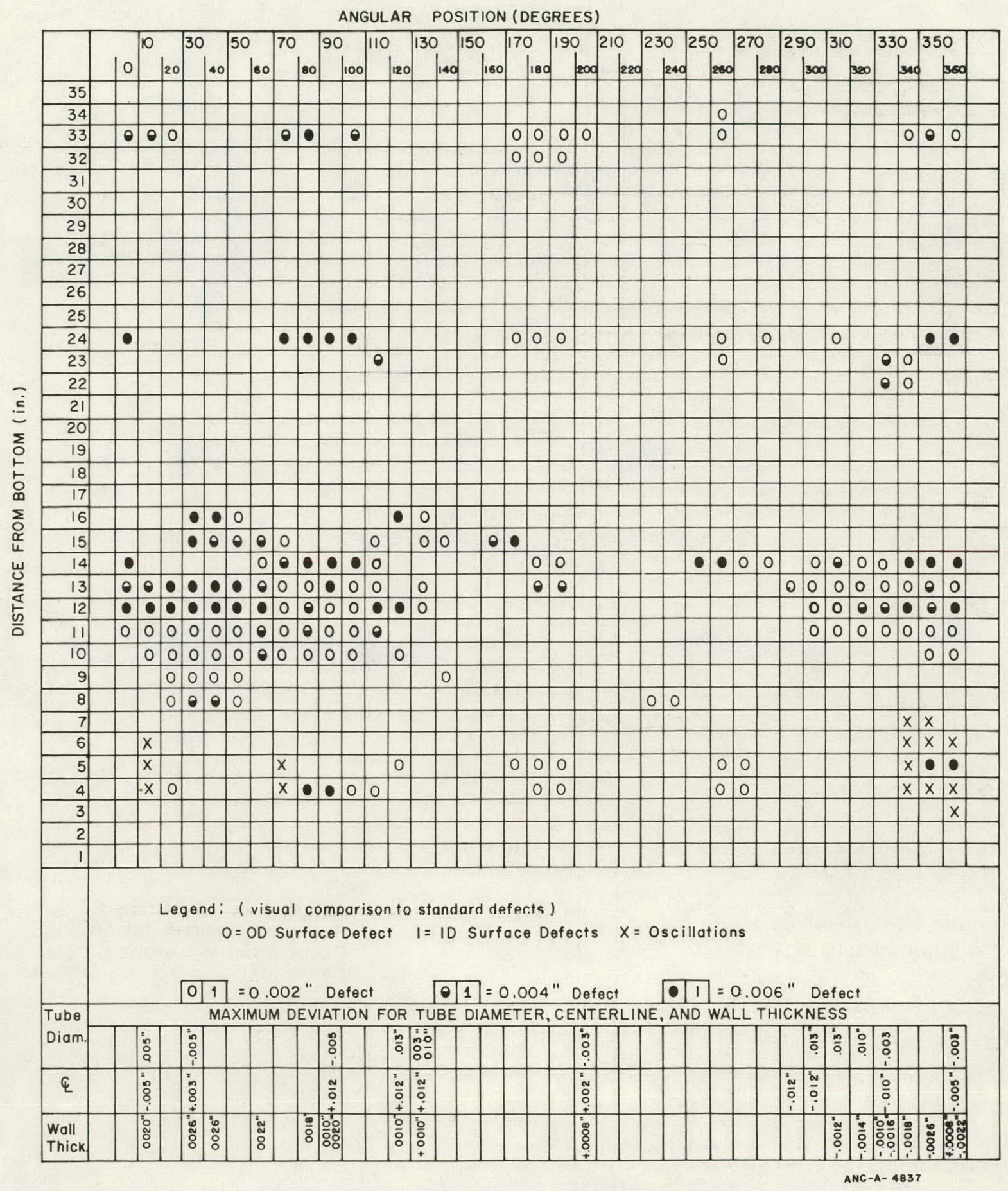

Fig. 21 Simplified defect chart of load-follow fuel rod 837 . 


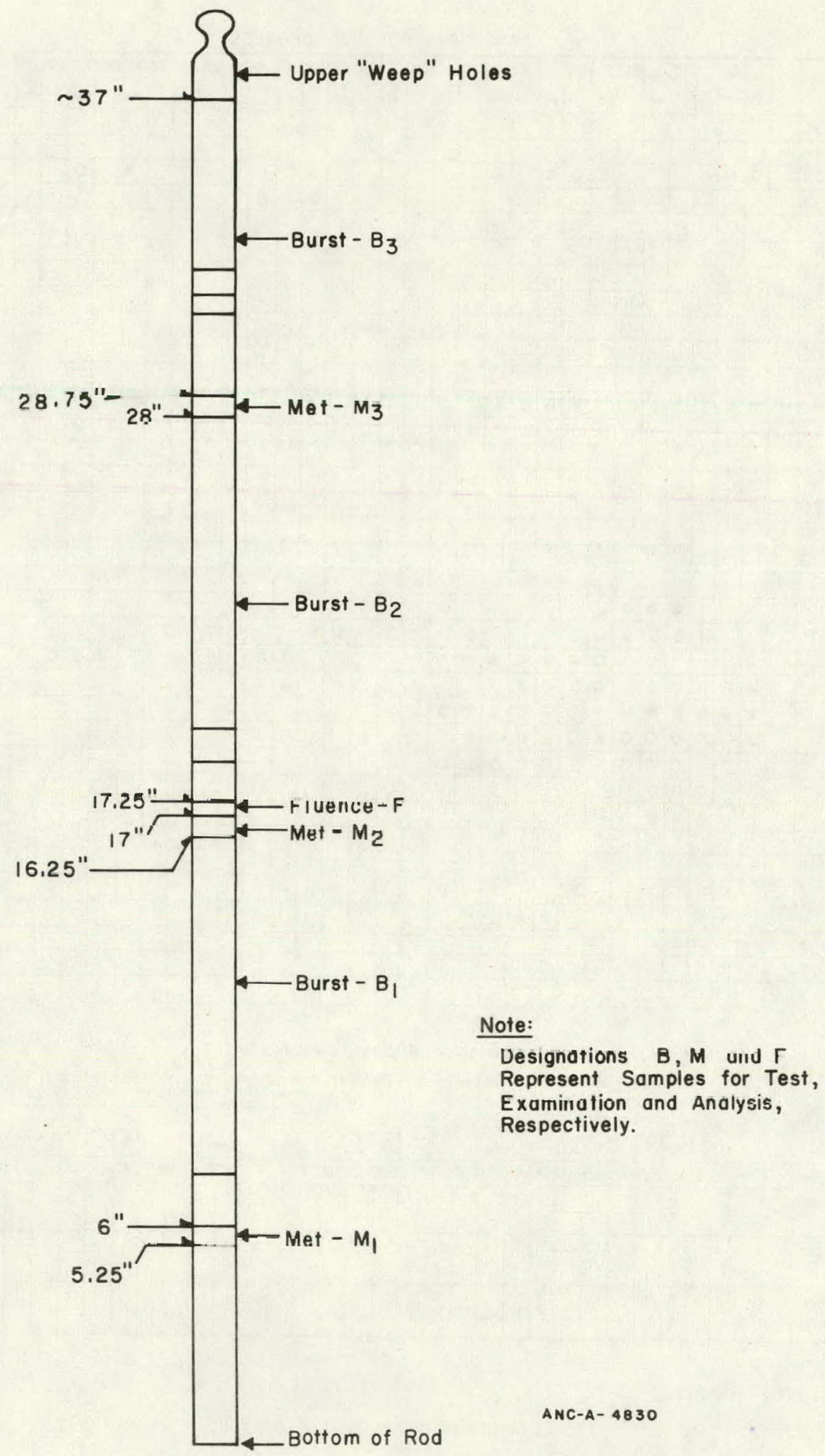

Fig. 22 Sectioning diagram - water tube STD-50 (all dimensions in inches). 


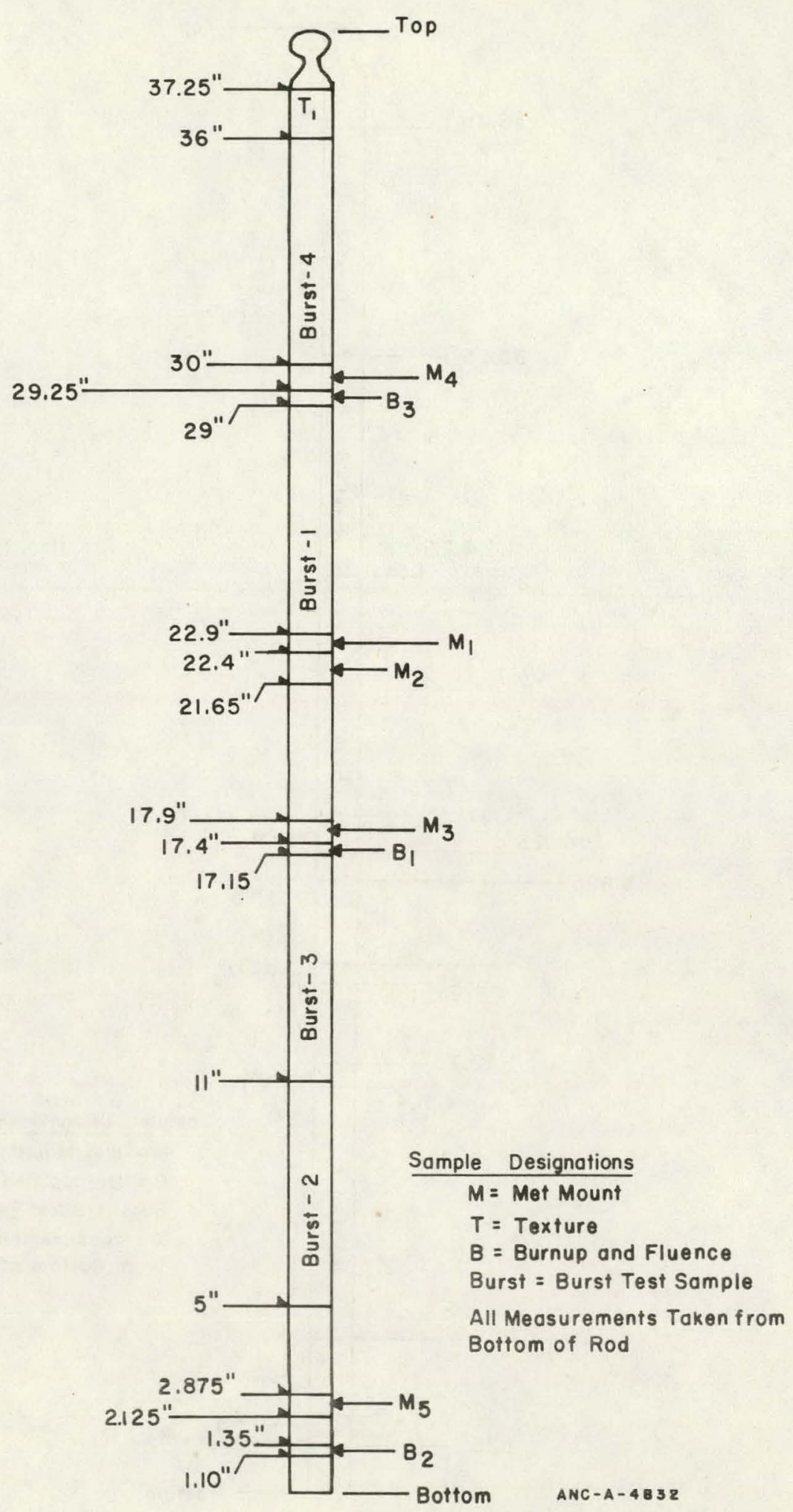

Fig. 23 Sectioning diagram - load-follow rod 864 (all dimensions in inches). 


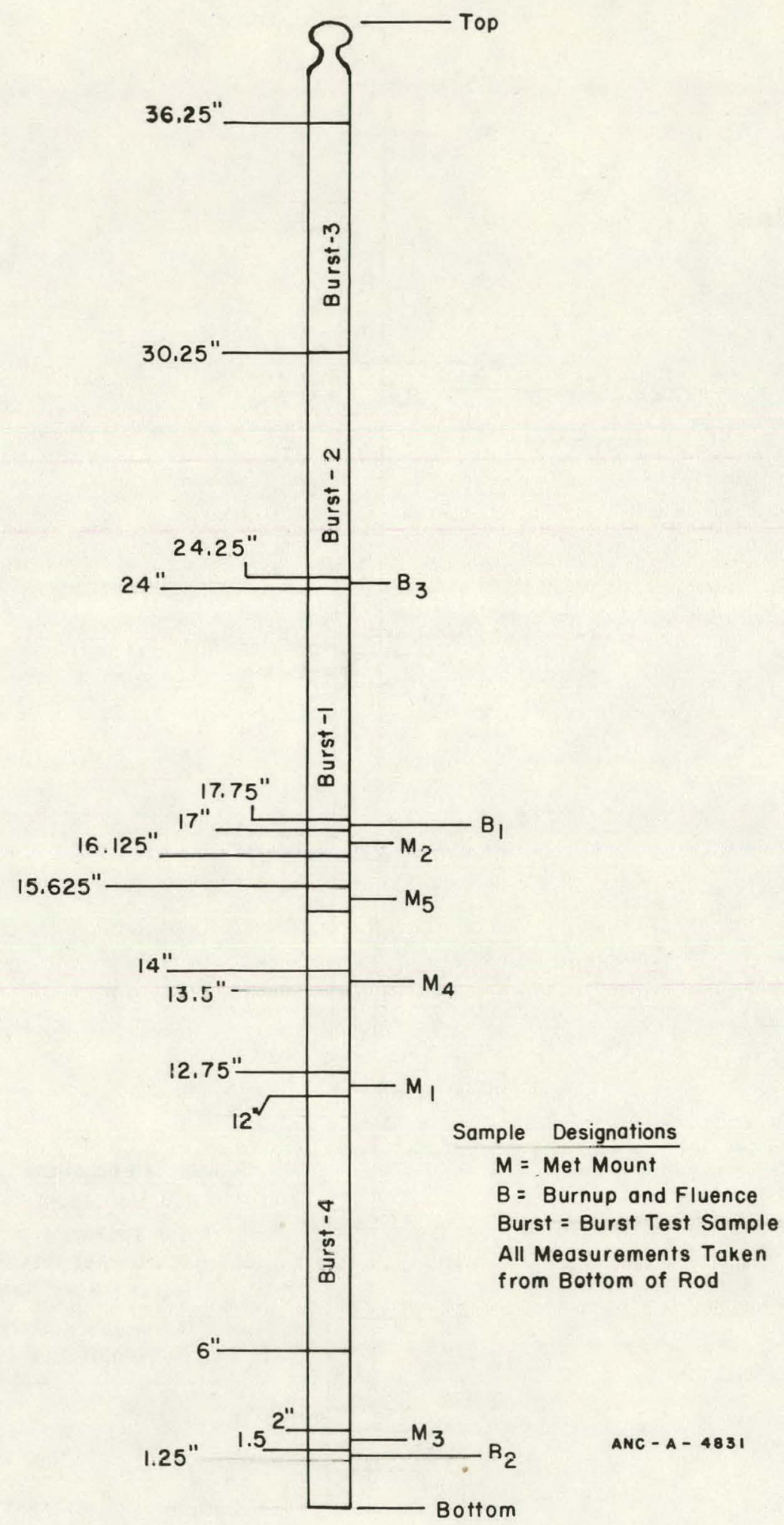

Fig. 24 Sectioning diagram - load-follow rod 837 (all dimensions in inches). 


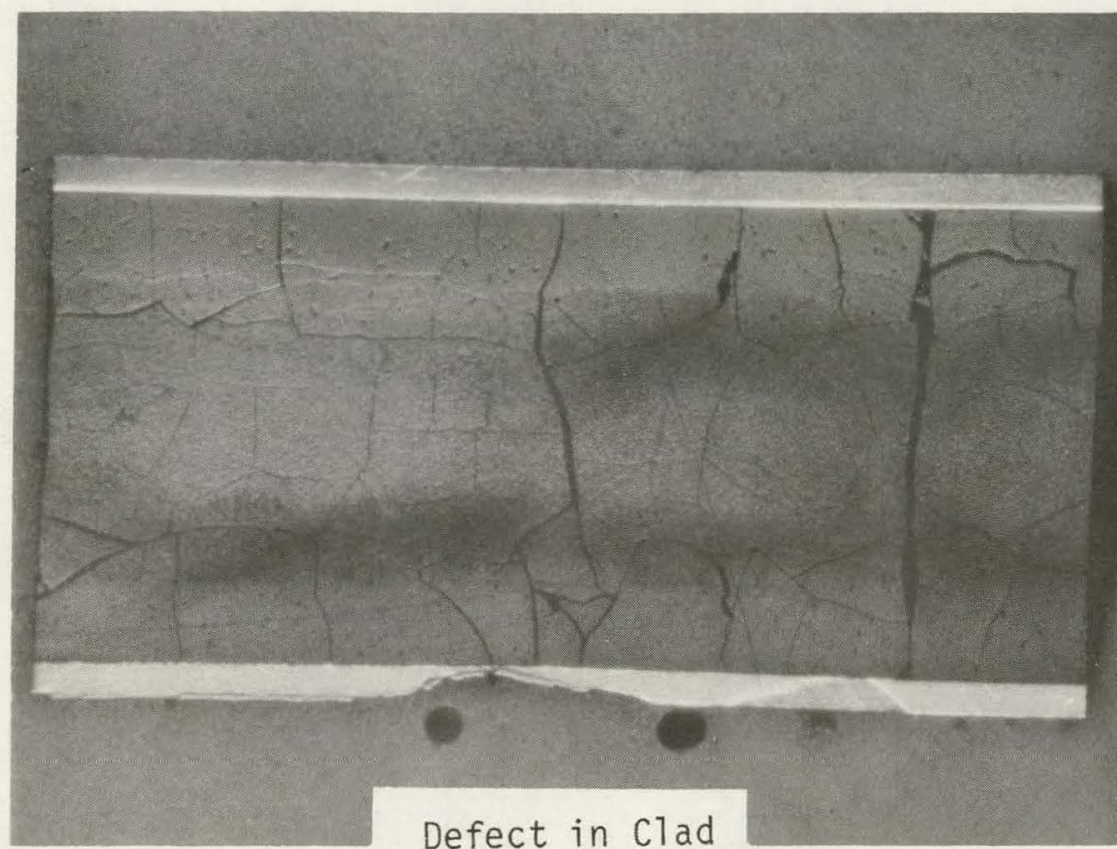

Mounting Material

Zircaloy

$\mathrm{UO}_{2}$

Zircaloy

Mounting Material

\section{$5.5 x$}

As Polished

Fig. 25 Longitudinal Section M-1 prepared from fuel rod 837 showing defect in surface of cladding.

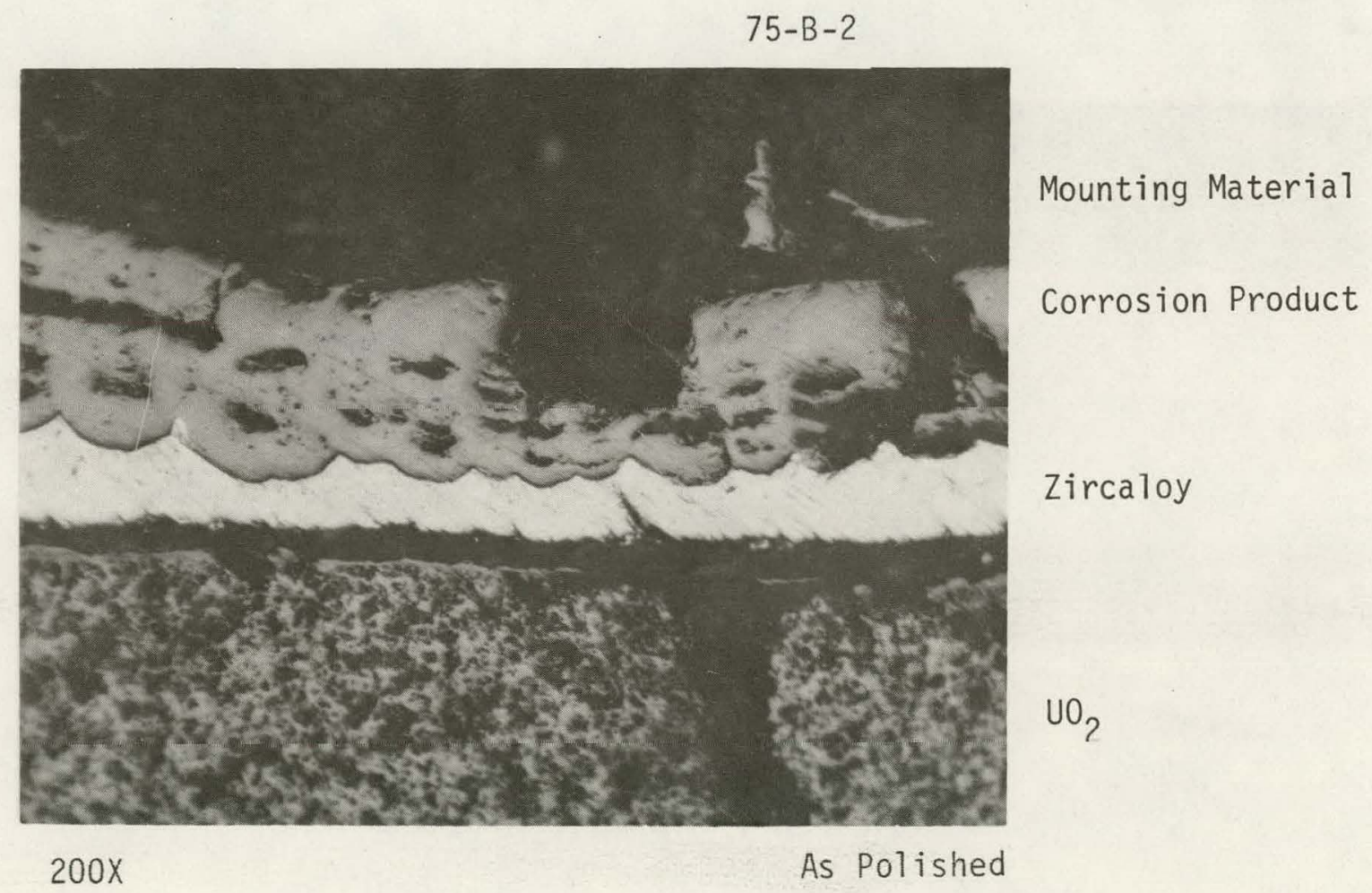

Fig. 26 Micrograph of surface defect found in Section M-1 of fuel rod 837, showing bottom of pit. 
$75-B-30$

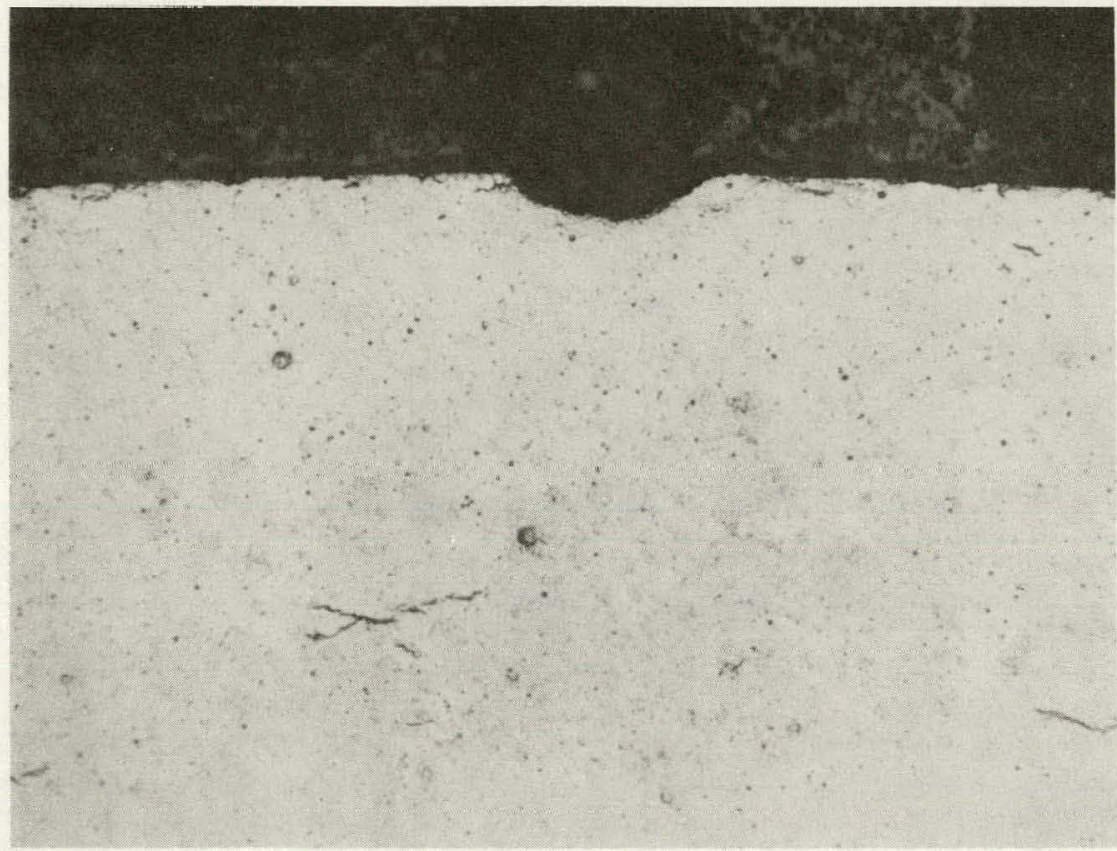

Mounting Material

Zircàoy

$200 x$

As Polished

Fig. 27 Micrograph of longitudinally-oriented groove found on OD surface of fuel rod 837 in Specimen M-3.

\section{$75-B-27$}

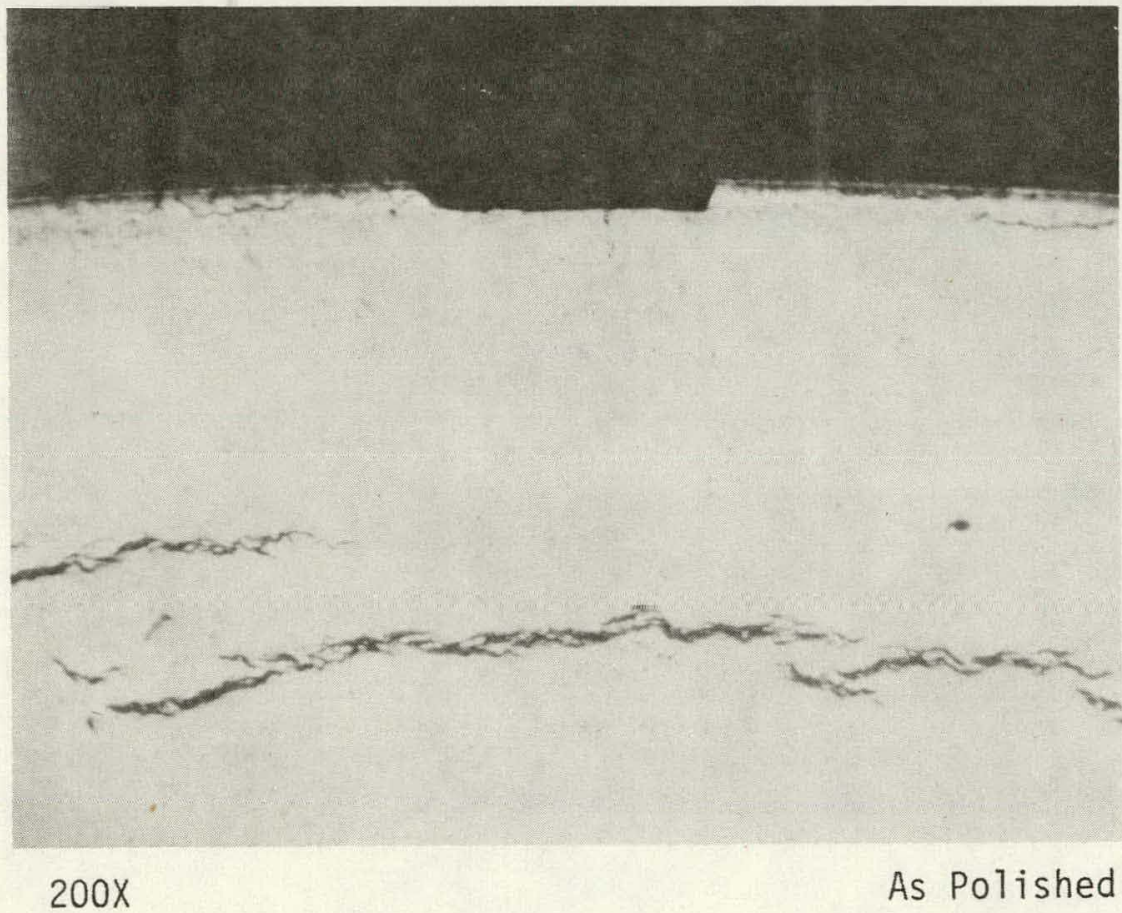

Mounting Material

Zircaloy

Fig. 28 Micrograph of surface defect found on OD of fuel rod 837 in Specimen M-4. 
$75-8-35$

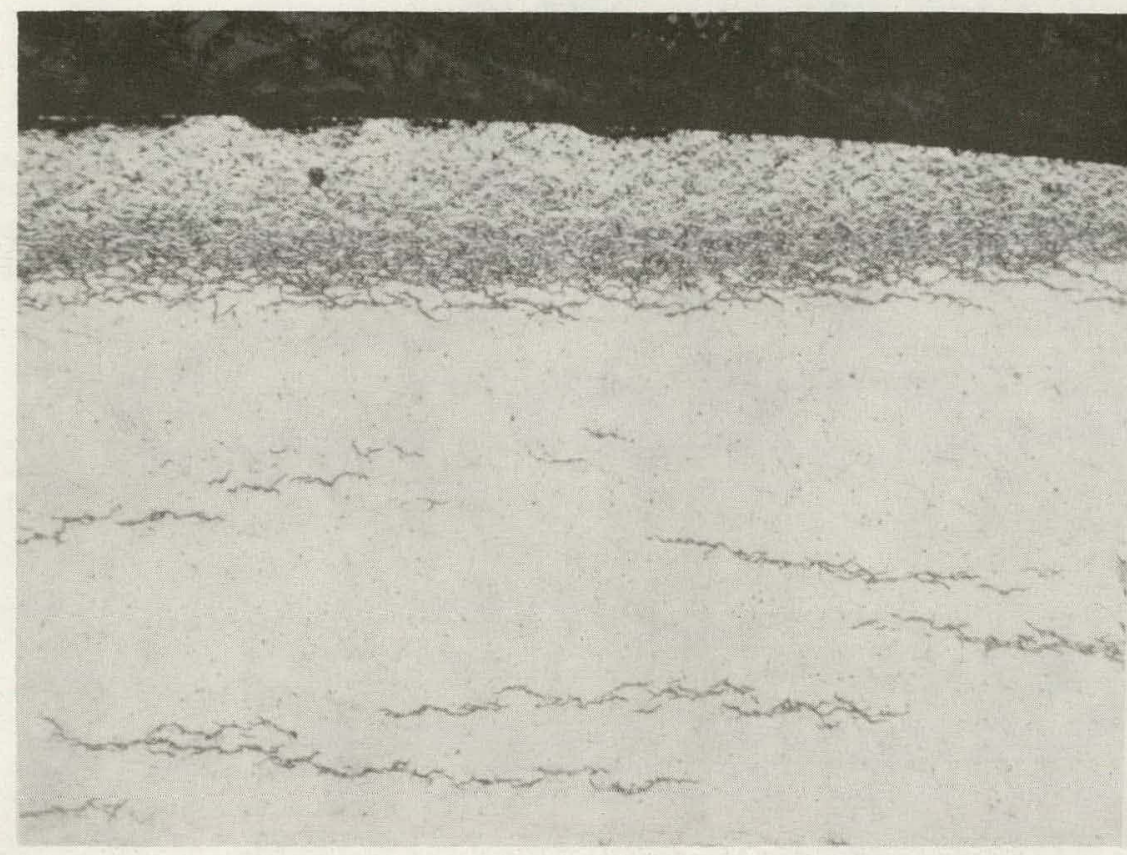

Mounting Material

$200 x$

As Polished

Fig. 29 Micrograph of cladding of fuel rod 837 taken 90 degrees from area shown in Figure 28, showing surface hydride layer.

One typical chart scan from rod 864 is shown in Figure 13. Surface (OD) indications are observed extending about 3 inches at the 20- to 23-inch region (measured from the bottom of the rod). Similar chart scans taken at 10-degree increments around the rod indicated that this region extended nearly around the rod and was quite pronounced over about 150 degrees of the circumference. Other OD indications appear scattered over much of the length of the fuel rod. Figure 16 attempts to illustrate graphically the extensive surface indicatiuns ubserved in the PEC charts. This pseudo-map covers only the region from 320 to 50 degrees, and includes all of the possible indications which could be identified. By comparison with the calibrating standards, the depth of these indications ranged primarily from 0.002 to 0.004 inch with a few in the 0.006 -inch range. Only a few scattered ID indications were noted, all below the threshold for significance. Cladding thickness changes of 0.0006 to 0.0008 inch, particularly in the 230 - to 300 -degree region, were readily associated with the OD indications. Throughout much of the length, diametral variations are pronounced ( \pm 0.010 inch). It was because of the extensive indications observed in the PEC scanning that rod 864 was selected for destructive examination. Some indication of the sensitivity of the PEC scanning, however, is illustrated in Figure 30. In this figure is shown a thin (approximately 0.002 inch thick) layer of corrosion product found on the surface of fuel rod 864. 


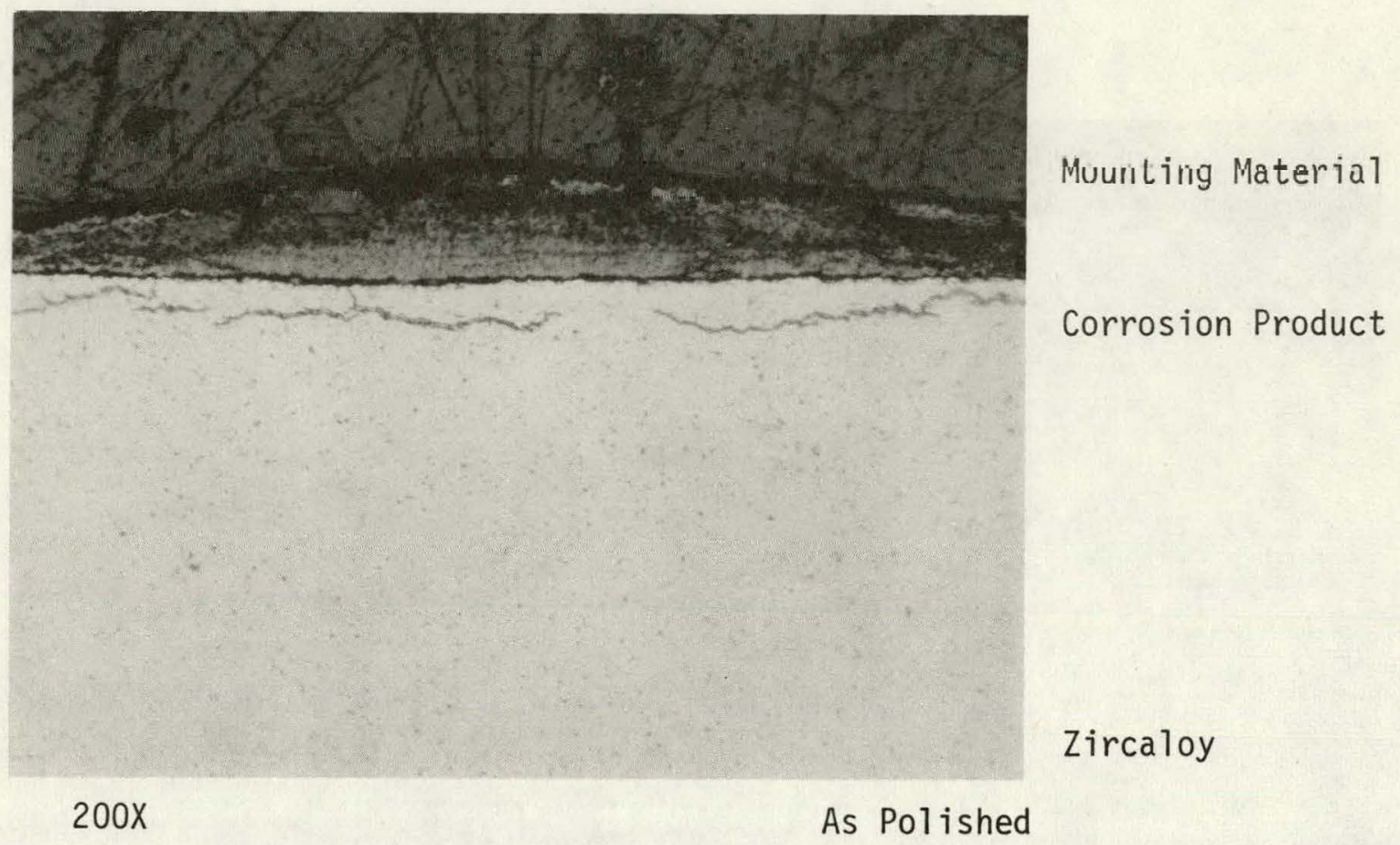

Fig. 30 Micrograph of cladding of fuel rod 864 showing corrosion product on surface.

Three of the five metallography specimens were taken for the express purpose of correlating with PEC-derived data. Specimen M-1, a transverse specimen centered at 22.65 inches from the bottom of the rod, was selected to view the area described above. Fxamination of this area (Figure 30 ) revealed isolated accumulations of corrosion product buildup in several areas, and shallow hydriding less than 0.0015 inch below the outside surface. None of the remaining specimens exhibited either of these phenomena. The corrosion products observed generally had a dimension of 0.015 to 0.025 inch in the rod transverse direction and had obviously survived the decrudding treatment. It has been demonstrated (on other rods) that either condition can result in "defect" indications.

Metallography specimen M-3, also a transverse specimen, was taken from an area which showed the greatest ovality on the diametral portion of the scans. Although not significant, defects were also indicated in this area. The section showed a variation of approximately $1.5 \%$ in the diametral measurements, which is in good agreement with the scanner results. No defects were observed during the polish/examination cycles, although a comparatively small amount of shallow hydriding was observed.

A longitudinal specimen, centered at 2.5 inches from the bottom of the rod, was taken in an area where the PEC traces showed a step as opposed to a blip or spike indication. The step in the traces applied to both the OD and ID traces and occurred on the 70-, 80-, and 90-degree scans. Although it was felt that the step was probably an electro-mechanical anomaly, the area was selected to verify the assumption. As expected, no indications were found. 
No indications of cracks, corrosion buildup, etc., were found in any of the samples outside regions where the PEC indicated defects were located.

\subsection{Water Tube}

Three metallographic samples were taken from the water tube in the areas marked in Figure 14. Specimens $M-1$ and M-2, covering regions of extensive OD and ID defects respectively, were prepared with longitudinal surfaces exposed. Specimen M-3 was a transverse section through an area containing several apparently unrelated defects.

The region of interest in specimen $M-1$ showed a small scuff mark (approximately $1 / 16$ inch across by $1 / 8$ inch long) on the OD surface prior to mounting. Examination of the polished metallography specimen indicated extremely localized variations in the OD surface ranging from 0.001 inch below to 0.002 inch above nominal surface.

A disturbed area on the ID surface of specimen M-2 was found to extend only 0.0008 inch into the wall at its deepest point (Figure 18). The size of the defect seems too small compared to the indications of the PEC scan and pseudo-map. It appears that either the deepest part of the defect was polished through during the repetitive polish/examine cycle, or the length of the disturbed area produced a relatively large indication.

A second, very small ID defect (approximately 0.0005 inch deep) with no surrounding distortion, located approximately 180 degrees from the first defect, was found. This defect appears, however, to have been too small for the PEC to pick up, since no indication could be found on the PEC traces. With the exception of some surface roughening (which was interpreted as noise on the PEC system) on a portion of the ID surface of specimen M-2, this is the only example of a defect observed in metallography that did not appear in the PEC charts."

Specimen M-3 was taken to evaluate the OD indication shown on the pseudo-map (Figure 14) at 200 degrees and approximately 28 inches from the bottom of the rod. The defect indication proved to be two flat-bottomed longitudinal grooves. Each groove (Figure 19) was approximately 0.005 -inch-wide by 0.00075 -inch-deep, and separated from its companion by 0.008 inch. The ID indications proved to be relatively minor deformations with an apparent longitudinal orientation. The 0 -degree/28-inch indication corresponds to the irregularities shown in Figure 20. Micrographs are only a few thousandths of an inch apart and are typical of what was observed in the other two areas. 


\section{DISCUSSION}

\section{GENERAL}

Our experience with the PEC technique and the equipment designed at INEL and ANL was generally most satisfactory. The design, which combined profile, wall thickness, and defect data acquisition all in one scan, saved countless hours of examination. Nonetheless, there are some inherent limitations in the PEC technique and some deficiencies in the as-built equipment, which merit noting. These are discussed here primarily to indicate some improvements which may be made in the existing equipment or which may be incorporated in a future design.

\section{LIMILAIIONS OF TFCHNIQUTSS}

The $\mathrm{PEC}$ technique is predominantly sensitive to defects lying in the longitudinal plane with respect to the scan direction and considerably less sensitive to transverse type defects. In our equipment it was virtually impossible to observe a 0.002 -inch-deep machined notch in the transverse plane. This limitation could possibly have been eliminated by scanning in a spiralling motion, but interpretation of the data would almost certainly have required a computer.

Sensitivity of the PEC detection is a function of the scanning speed. In the design and in laboratory preoperational testing, the scan velocity must be optimized for maximum sensitivity. Then, because of the high scanning speed required for sensitivity (approximately 2 inches/sec), it is not possible to slowly search back and fortl over a suspected defect for enhanced characterization.

Defect size estimation is based on comparison with calibrating standards. Actual defects lying in other than purely longitudinal or transverse planes can be evaluated as being "at least" equal to a certain size of standard; the actual size of a diagonal defect could be somewhat larger. This deficiency may well be applicable to all NDT techniques scanning in an axiạl mode.

Axial scanning provided relatively good resolution of the extent of a defect in angular displacement but very little information on the extent of the defect in the axial direction.

\section{EQUIPMENT LIMITATIONS}

(1) Correlation of the start, stop, and linearity of the axial scan of the strip chart recording with the PEC equipment was difficult 
and subject to some judgment errors. Use of a stepping motor, or equivalent, to control the axial traverse and the use of start and stop reference calibration marks on the strip chart and fuel rod would resolve this deficiency.

(2) The acme-threaded lead screws for the axial drive train required frequent oiling. Providing adequate oil for smooth motion to reduce drag was difficult to accomplish remotely in the hot cell. Too little oil appeared to result in a slower and somewhat nonuniform axial traverse; too much oil resulted in splatter on equipment and even on the walls of the hot cell.

(3) The voluminous data (37 strip charts, each with six data scans for each rod) made "hand" reduction a lengthy, tedious operation. Recording of the data redundantly on magnetic tape which could then be evaluated by an appropriately developed computer program would be a real advantage in examining a large number of fuel rods. Computerization could also reduce the potential for human error. Development of a program to provide the "human judgment" necessary may be difficult.

(4) The thickness sensor and the defect sensor are separated axially by about 0.8 inch; both sensors are separated angularly by 90 degrees from the LVDTs. These offsets make correlation of the six line scans on each chart difficult. The computerized data handling proposed above could provide automatic axial and azimuthal correlation of the data.

(5) Most of the fuel rods to be tested in the Fuel Behavior Program will have instrument leads emerging from the top end cap, and most will also include surface thermocouples. Present PEC equipment has no provision for handling this instrumentation. We believe that relatively minor equipment changes would permit scanning rods with top end cap leads, but surface instrumentation presents a more difficult problem. At best, it appears that the latter rods can be scanned only in regions free of surface instrumentation.

(6) As in most NDT techniques, the evaluation of data is largely dependent on the use of good calibration standards. We believe the defect and centerline (straightness) standards adequately met the requirements, but the thickness standard left something to be desired. The steps were not sufficiently uniform, such that calihration with PFC. response could he easily established. This problem was at least partly the result of our decision to machine the thickness steps on the inside surface while retaining the constant outer surface for ease in traversing. Improved thickness standards are needed and further calibration is necessary. 
(7) The diameter measuring capability of the existing equipment has not been fully utilized. New standards are necessary to evaluate the accuracy and precision of the diametral measurements.

(8). The ability of the PEC inspection method to determine cladding hydriding and fuel-cladding interaction needs to be more fully evaluated. 


\section{REFERENCES}

1. W. J. Quapp and C. M. Allison (Aerojét Nuclear Co.), Fuel Behavior Program Project Description Document: Irradiation Effects and Simulation, Private Communication (January, 1975).

2. C. J. Renken, Progress Report on Nondestructive Testing by Electromagnetic Methods, ANL-6414 (July 1962).

3. C. J. Renken, A Pulsed Electromagnetic Test System Applied to the Inspection of Thin-Walled Tubing, ANL-6728 (March 1964).

4. T. H. Busse, D. R. Wood, N. S. Beyer, Nondestructive Inspection of.EBR-II Fuel Jacket Tubing Using Electromagnetic Techniques, ANL-7334 (May 1967).

5. R. R. Asamoto, R. F. Bacon, A. E. Conti, G. P. Wozadlo, Evaluation of Irradiated Fuel Rods with Pulsèd Eddy Current, GEAP-B928 (December 1972).

6. H. B. Patel, A. Ditchum, A. E. Hunton, Ultrasonic Testing of Irradiated Fuel Sheathing, Atomic Energy of Canada, Ltd., Report AECL 4655 (November 1973).

7. Nondestructive Testing Personnel Qualification and Certification, Recommended Practice No. SNT-TC-1A, Supplement E, Eddy Current Testing Method. American Society for Nondestructive Testing, 1968 edition.

8. G. W. Gibson and B. A. Murdock (eds.), Characteristics of $\mathrm{UO}_{2}-$ Zircaloy Fuel Rod Materials. From the Saxton Reactor, (to be published).

9. M. E. Yancey, E. H. Porter, H. R. Hansen, Inspection System for Zircaloy Clad Fuel Rods, ANCR-1259 (October, 1975). 
THIS PAGE

\section{WAS INTENTIONALLY LEFT BLANK}


APPENDIX

SUMMARIZED OPERATING PROCEDURE FOR PEC 
THIS PAGE

\section{WAS INTENTIONALLY LEFT BLANK}




\section{APPENDIX \\ SUMMARIZED OPERATING PROCEDURE FOR PEC}

\section{SCANNING CALIBRATION STANDARD}

With the LVDTs retracted, the calibrating standard rod is inserted into the scanning equipment. The offset notch on the bottom of the rod is placed on the offset lip on the base pedestal, thereby indexing the zero position of the PEC sensors. The zero position for the LVDTs is 90 degrees counter-clockwise (viewed from bottom of rod) from the sensors (Figure 6). The LVDTs are then closed against the calibration rod.

The platform is elevated to the top position, and the scan made from top to bottom using a down speed of 1.8 inches/sec. The OD defects are at 50 degrees on the Standard, so the table is rotated counter-clockwise to 50 degrees, and the scan is made. Any adjustments necessary are made at this time so as to have the traces comparable with the previously run standard charts. The diameter, centerline, and all thickness pen settings are zeroed on the chart...The 50-degree position is also changed slightly (a degree or two) in order to get the maximum signal from the $O D$ defects. This is usually a onetime procedure for calibration. A similar adjustment may be required for the ID defects at the 230-degree position.

After completing the downward scan for the OD defects, the standard rod is rotated 180 degrees counter-clockwise to the 230-degree position for the ID defects. The platform is elevated to the top, and the scan made on the downward pass. After making the necessary adjustments on the OD scan, the ID scans usually fall into place without any further adjustments.

When making a scan, the two "Mark Event" buttons are pressed to make a mark on each side of the chart. This indicates the start position on the chart. The "Chart Drive Speed" is set by pushing in the " 25 " Chart Speed button. To start the scan the Chart Dirive Toggle Switch and the Down Drive Switch must be energized simultaneously so that the chart drive and scan will start at the same time. When the scan is completed, the platform stops automatically at the bottom.

The chart is shut off manually with the toggle switch, and the chart speed reset to position 1 or to the stop' position. The Rotary Indexer is returned to the zero position at which time the Azimuthal Zero light comes on.

\section{SCANNING FUEL ROD OR WATER TUBE}

The LVDTs are opened and the calibrating standard rod removed. A fuel rod or water tube to be scanned is then positioned by first placing the top of the rod in the top holding 
bracket and then placing the offset notched bottom of the rod against the offset lip of the base pedestal. Verification that the rotating index table is at zero is made by observing that the Azimuthal Zero light is lit. The 'LVDTs are closed by pressing the LVDT position override. The Do Not Scan light and the Retracted light will go out. The Scan light will then come on, and the PEC instrument is ready for scanning.

The Table Drive Lever is pushed to the UP position and the Scanning table is raised to the top of the column. The two Mark Event buttons are pressed to make the starting mark on the chart; the 25 Chart Drive Speed button is pressed and the Chart Drive and Scanner Down Drive started simultaneously. The first scan at 0 degrees is thus initiated.

When the scanning table reaches the bottom it automatically shuts off. The Chart Drive is shut off, and the 1 button on the Chart Drive Speed is depressed.

The Rotary Indexer is next set at 10 degrees by turning the Pulse Control to the 1,000 reading (100 pulses equal 1 degree). The Rotation Indexer is set on (-) for counter-clockwise direction. When the Index Start Button is pressed, the table will automatically turn to the 10 degree position. This can be done while the scanning table is returning to the UP or top position. The rod is thus scanned at 10-degree intervals for 36 scans, one complete revolution of the rod. The "beam angle" of the sensors is such that the entire surface of the rod or tube is covered in this manner. 
DISTRIBUTION. RECORD FOR ANCR-1282

\section{External}

320 - NRC-3, Water Reactor Safety Research Fuel Behavior

2 - H. J. C. Kouts, NRC

\section{$\underline{\text { Internal }}$}

1 - Chicago Patent Group - ERDA 9800 South Cass Avenue Argonne, Illinois 60439

3 - A. T. Morphew, Clasșification and Technical Information officer ERDA-ID Idaho Falls, Idaho 83401

1 - R. J. Beers, ID

1 - P. E. Litteneker, ID

I - R. E. Swanson, ID

1 - V. A. Walker, ID

1 - R. E. Wood, ID

11 - INEL Technical Library

80 - Authors 